\title{
LA MIGRACIÓN INTERNA EN MÉXICO, 1950-1960 Aspectos metodológicos y cuantitativos
}

\author{
Gustavo Cabrera * \\ El Colegio de México
}

\section{INTRODUCCIÓN}

En México, como en otros países de América Latina, o en otras regiones del mundo, se observa una carencia de estudios sistemáticos referentes a los desplazamientos de población dentro de sus fronteras nacionales. En comparación con otros campos de la demografía formal, el de la migración interna es uno de los menos desarrollados tanto en sus aspectos técnicos como en su relación con otras ciencias sociales. Es probable que la falta de preocupación por el estudio de esta área de la demografía se deba a la escasa y débil información estadística, la cual no permite una base sólida para un análisis formal del fenómeno. Muy poco progreso se ha dado en este sentido y prácticamente ningún avance se ha hecho para la obtención de nueva información a través de los censos o de los registros continuos.

Sin embargo, durante el último decenio los demógrafos han cobrado conciencia de la gran importancia que tienen los movimientos migratorios en las estimaciones intercensales y postcensales de la población a nivel regional o local. De la misma manera, los encargados de la planeación de un país, cuando manipulan las complejas variables que intervienen en los programas regionales de integración económica y social, han sentido la necesidad de analizar los efectos que la migración ha producido o probablemente producirá en las poblaciones.

Además del efecto cuantitativo que estos movimientos tienen en el tamaño de la población, los migrantes poseen características cualitativas especiales que resultan de un hecho importante: ellos no son una muestra aleatoria representativa de la población del país o de sus regiones, sino que difieren en su composición por sexo, edad y características socioeconómicas, tanto en el área de origen como en la de destino. Estos aspectos diferenciales entre la población migrante y no migrante son temas de investigación por parte de sociólogos, ecólogos, economistas, etc., y cada uno debe analizarlos con el fin de

* El artículo que se presenta es parte de un trabajo más extenso realizado por el autor en la Oficina de Investigaciones de Población de la Universidad de Princeton, durante el año académico 1966/67. El autor desea expresar su reconocimiento por la valiosa ayuda que le prestó el profesor Ansley J. Coale, director de la propia Oficina, en la preparación del documento. 
explicar las causas y efectos del proceso migratorio de acuerdo con los objetivos de su área específica de estudio.

Debido a que la migración interna es un proceso que se relaciona con gran variedad de problemas sociales, económicos y políticos de un país, hay extensa necesidad de su conocimiento interdisciplinario. $\mathrm{La}$ principal fuente para su estudio son las estadísticas de población y de ahí que gran parte de la responsabilidad para proporcionar este cuerpo de información descanse en la ciencia demográfica.

Las estimaciones cuantitativas son el primer paso en los estudios de los movimientos migratorios de un país y en este sentido se ha orientado el trabajo que aquí se presenta.

Las fuentes de las estadísticas de población en México son los censos de población, que se han llevado a cabo cada diez años desde 1900, y los registros vitales. En ninguna de ellas puede obtenerse información directa de los cambios de residencia de la población. Debido a esto, diferentes métodos han sido desarrollados para evaluar en forma indirecta la dirección y magnitud de las corrientes migratorias, siendo casi todos ellos producto de la información disponible. En realidad, estos métodos sólo deben ser considerados como sustitutos de procesos más lógicos y exactos.

El procedimiento que está más cercano a la medición directa del fenómeno migratorio se basa en la información censal sobre el lugar de residencia y el lugar de nacimiento de la población. Los métodos indirectos están basados, en su mayoría, en las relaciones que se establecen entre el crecimiento total de la población y el crecimiento natural a través de estimaciones de la natalidad y la mortalidad, o bien en el uso directo de los registros de nacimientos y defunciones. Estos últimos procesos son también conocidos como métodos residuales debido a que el volumen de la migración es obtenido por diferencia entre el crecimiento total y el natural.

En este trabajo se presentan diversas estimaciones de la migración interna en México en el período 1950-1960, que corresponden a cuatro procesos que son tradicionalmente conocidos en la literatura demográfica, a saber:

1) mediante la utilización de la información censal sobre el lugar de residencia y el de nacimiento de la población en 1950 y 1960 ;

2) con la información censal de la composición por edad de la población en 1950 y 1960 e índices de sobrevivencia de tablas de vida;

3) con la misma información censal que el punto anterior y una estimación de los índices de sobrevivencia censales, y

4) utilizando la población total censada en 1950 y 1960 y los registros de nacimientos y defunciones para el período.

Un examen más detallado se ha hecho con el método basado en el lugar de nacimiento de la población, considerando que responde al tipo de información que usualmente se encuentra disponible en los países de América Latina. En este proceso se ha introducido un ajustamiento con objeto de eliminar o al menos reducir su principal debi- 
lidad: la mortalidad intercensal de la población migrante existente en 1950, la que es motivo de fuertes desviaciones en las estimaciones.

En los otros métodos, se incluyen breves explicaciones sobre sus procesos y limitaciones, así como también se efectúan ajustes con objeto de mejorar sus estimaciones.

Finalmente, se hacen algunos comentarios sobre la magnitud y característica de las diferencias que se obtuvieron entre las diversas estimaciones.

\section{CONCEPTOS BÁsICOS}

E1 término "migración interna" se usa generalmente, en su más amplio sentido, para referir los movimientos de uno o más individuos de un lugar a otro, dentro de las fronteras de un país. En realidad, no se ha llegado a establecer una definición de este proceso que pueda ser aplicada universalmente. Hay múltiples definiciones que dependen de las condiciones particulares del área de estudio y de la información disponible.

No obstante, se han hecho intentos por esclarecer el concepto, tratando de eliminar ambigüedades que se presentan por la naturaleza propia del fenómeno. Algunos autores ${ }^{1}$ consideran que la migración interna se refiere a los cambios de lugar de residencia de la población, dentro de un país, en donde el movimiento se efectúa de una comunidad a otra, debiéndose recorrer una distancia que sea suficiente para que el cambio les represente un nuevo ajuste a las condiciones económicas y sociales propias de la comunidad receptora. Esta importante definición considera a uno de los elementos básicos en el proceso migratorio: la distancia social o geográfica recorrida. En función de ella se determina si una persona tiene la calidad de migrante o no.

De acuerdo con otros autores, ${ }^{2}$ la definición aceptada de migración interna es el cambio de residencia de una comunidad o de una unidad geográfica claramente especificada, a otra dentro de las fronteras nacionales.

Para los propósitos estadísticos del presente trabajo, la definición de migración interna estará basada en la elección de unidades geográficas y referida a un intervalo de tiempo establecido.

\section{Las unidades geográficas}

Considerando que el espacio es continuo, la distancia relacionada con el cambio de residencia puede variar ampliamente: una persona cambia de residencia dentro de la misma comunidad y este movimiento representa una distancia recorrida de unos cuantos cientos de metros, o bien puede trasladarse de una comunidad a otra que se encuentre separada por varios miles de kilómetros. Ambos casos constituyen

1 D. J. Bogue, Internal Migration, United Nations Seminar on Evaluation and Utilization of Population Census Data in Asia and the Far East, E/CN.9/ Conf. $2 /$ L.21, 1960.

2 Dorothy S. Thomas, Research Memorandum on Migration Differentials, Social Science Research Council, Bulletin 43, Nueva York, 1938. 
migración interna y no hay duda del diferente significado que tienen estos dos tipos de movimientos.

E1 procedimiento común para elegir la unidad geográfica es utilizar las divisiones político-administrativas de un país y definir la migración interna en términos del movimiento desde una división hacia otra de la misma categoría. En esta forma, la migración puede referirse a los movimientos que se producen entre ciudades, municipios, entidades federativas, etc., o bien entre regiones que comprendan municipios o entidades completas o grandes zonas que se formen de acuerdo con el tamaño de las ciudades, como es el caso de las áreas urbanas y rurales.

Debido a la naturaleza del procedimiento seleccionado para estimar el volumen migratorio, se han escogido en el presente trabajo como unidades geográficas las entidades federativas del país. Es decir, se medirá la migración interna en términos interestatales.

Esta adopción de las unidades geográficas tiene consecuencias importantes en el número de los migrantes. El volumen de la migración dependerá del tamaño y la forma de las unidades geográficas y de la distribución de su población dentro de ellas.

En cuanto al área, se ha demostrado en varios estudios que el número de migrantes decrece rápidamente cuando la distancia de la migración aumenta. Es decir, en general, a mayor tamaño de las unidades espaciales, menor el número de migrantes. ${ }^{3}$ De esta forma se tendrá que en México la migración interestatal, en términos de 32 unidades geográficas, será apreciablemente menor que la definida respecto a municipios, de los que hay más de 2000 unidades; y mucho menor aún sería una supuesta migración interregional.

Si todas las entidades federativas de México tuvieran la misma superficie, sus respectivas poblaciones, con relación a esta característica, tendrían las mismas posibilidades de migrar, independientemente de otras consideraciones e influencias. Al no darse esta paridad, podría pensarse que existen probabilidades diferenciales de adquirir la calidad de migrante, dependiendo estos diferenciales del tamaño de las unidads espaciales seleccionadas.

Una limitación más del método de selección de las unidades espa. ciales es que no hay verdadera separación entre los movimientos a larga distancia y los locales. ${ }^{4}$ Una persona que se desplaza apenas unos cuantos metros, significando eso el cruce del límite de la unidad geográfica, adquiere la calidad de migrante. Por el contrario, la persona que cambia de residencia de un extremo a otro dentro de la unidad de observación, no se considera migrante debido a que sigue viviendo dentro de las fronteras del área escogida para identificar la migración. Esto significa que muchos migrantes genuinos no son tomados en cuenta, mientras que aquellos que prácticamente no cambiaron, ni sufrieron alteraciones importantes en su forma de vida, son contados como migrantes. Podría pensarse que estos casos se compensan y que, esta-

3 En Estados Unidos se estimó que durante 1935-1940 migraron 15.7 millones de personas entre unidades geográficas pequeñas ( 3000 counties); 6.5 millones entre entidades ( 49 entidades) y 3 millones de migrantes interregionales ( 4 regiones). Véase S. E. Lee, "Population Redistribution and Economic Growth; United States, 1870-1950", The American Philosophical Society, Filadelfia, 1957, p. 10.

4 Movimientos locales son aquellos que se desarrollan dentro de las fronteras de las unidades geográficas. 
dísticamente, el monto total no sufre distorsiones significativas. Pero esto no puede afirmarse que suceda, y ciertamente no es verdadero cuando se quieren estudiar las motivaciones y características de los migrantes.

Otros aspectos que se relacionan con la unidad espacial seleccionada son la forma y la distribución de la población dentro de dichas unidades. En términos amplios, una concentración de población a lo largo de la línea divisoria de las entidades daría como resultado una mayor migración interestatal en comparación con otros estados cuya población estuviera distribuida uniformemente en su superficie o localizada en el centro.

En resumen, el método de elegir áreas geográficas para definir la migración tiene deficiencias que deben ser reconocidas. El monto de la migración observada en una población depende del tamaño de las áreas de las unidades usadas con propósitos de definición. Las unidades pequeñas tenderán a desarrollar una migración más alta (en términos relativos), debido a la proporción más elevada representada por los movimientos a corta distancia. Esto significa también que no son del todo comparables los montos de migración, medidos a través de alguna relación, de las unidades que no sean de la misma categoría; quiere decir, además, estadísticamente, que la migración de las unidades de diferentes tamaños tampoco es del todo comparable.

A pesar de las limitaciones anotadas, no existe alternativa satisfactoria que pueda ser usada en combinación con la información censal. Sin embargo, además de la ventaja práctica que supone la adopción de unidades geográficas, cuando se usa el mismo tipo de unidades en la estimación de la migración en diferentes períodos de tiempo, todos los intervalos comprenderán las mismas desviaciones, y lo más probable es que las tendencias observadas en el comportamiento de la migración sean reales.

\section{El intervalo de tiempo}

La migración es un acontecimiento continuo en el tiempo. Para analizarla, es necesario distinguir períodos con información separada respecto a cada uno de ellos. En forma semejante a la unidad espacial, la selección del intervalo de estudio influirá en el volumen de los migrantes.

Debido a que la información básica de la presente estimación proviene de los censos llevados a cabo en 1950 y 1960, el intervalo será el período intercensal 1950-1960. Un período de esta amplitud tiene efectos importantes en el volumen de los migrantes. El número de éstos aumenta cuando el tiempo de referencia se extiende. Es decir, la probabilidad de migrar se incrementa a medida que se amplía el intervalo durante el cual puede ocurrir el acontecimiento; los individuos están expuestos mayor tiempo al riesgo de migrar.

Asimismo, el número total de migrantes, durante el intervalo, incluye tanto a los migrantes sobrevivientes como a los que mueran antes del fin del período. Cuando dicho intervalo abarca un número considerable de años, el volumen de las defunciones de los migrantes puede alcanzar un monto apreciable. 
Por último, los múltiples movimientos que la población efectúa durante el periodo establecido serán más frecuentes cuanto mayor sea el intervalo. Debido a la naturaleza de la información, este problema es imposible de controlar ya que sólo se identifica a la población migrante al principio y al final del período intercensal, desconociéndose los movimientos intermedios.

\section{Definiciones}

Combinando las dos características anteriores -unidades espaciales e intervalo de tiempo- se establecen los conceptos que se utilizarán en la medición de la migración.

Población no migrante: personas que al momento de llevarse a cabo los censos de 1950 y 1960 se encontraban residiendo en la entidad en que nacieron.

Población migrante: personas que al momento de llevarse a cabo los censos estaban residiendo, en forma definitiva, fuera de su entidad de nacimiento.

Inmigración acumulada: el número de personas enumeradas en una entidad al tiempo de los censos y que nacieron fuera de la entidad de enumeración.

Emigración acumulada: el número de personas nacidas en una entidad particular y enumerada fuera de ella en los censos.

Migración neta acumulada: el balance entre la inmigración acumulada y la emigración acumulada. Este balance neto puede ser positivo y representar ganancia neta para la entidad, o negativo y significar pérdida neta.

Se ha usado el término "acumulada" para indicar a los sobrevivientes, a un tiempo dado, de todas aquellas personas que han cambiado de entidad de origen en cualquier momento comprendido entre su nacimiento y la fecha del censo. Es decir, la migración acumulada agrupa a personas que efectuaron el movimiento muchos años antes del censo y a personas con sólo unos días de haber llegado; no hay referencia al período en que migraron.

Inmigración intercensal: el número de personas que llegaron a una entidad diferente a la de su nacimiento, para residir en ella permanentemente, durante el período intercensal 1950-1960.

Emigración intercensal: el número de personas que salieron de su entidad de origen, en forma definitiva, durante el período intercensal.

Migración neta intercensat: el balance entre la inmigración intercensal y la emigración intercensal. Si el balance es positivo representa ganancia neta para la entidad durante el período intercensal: si es negativo significa pérdida neta.

\section{LA MIGRACTÓN TNTERNA EN FUNCIÓN DE LOS DATOS CENSALES SOBRE LUGAR DE NACIMIENTO}

Entre los métodos usuales de la estimación de la migración interna, se ha escogido el basado en la información censal sobre el lugar de nacimiento de la población, debido a la flexibilidad que tiene para 
proveer información de importantes aspectos de la migración interna, tales como el tamaño de las corrientes de los inmigrantes y emigrantes, la dirección y distancia de los movimientos y las características de la población migrante al tiempo de los censos.

\section{Descripción del método}

El procedimiento se basa en la información censal de 1950 y 1960 sobre la entidad de nacimiento de la población residente en ella. Esta información puede ser distribuida convenientemente haciendo uso de una tabla de doble entrada, en que las líneas identifican a la población según su entidad de nacimiento y las columnas su entidad de residencia. En otros términos, las líneas representan a los emigrantes en cada entidad, mientras que las columnas representan a los inmigrantes en cada entidad.

Si denotamos $I$ como el número de personas enumeradas a la fecha de los censos en un estado diferente al de su nacimiento y $E$ como el número de personas nacidas en una entidad y enumeradas en otras, podemos definir $I$ como los inmigrados acumulados en una entidad y $E$ como los emigrados acumulados de la misma entidad. La diferencia o el balance entre estas dos cantidades es la migración neta acumulada $(I-E=M)$. Estas estimaciones no están referidas a la migración durante algún período de tiempo definido, de suerte que el balance refleja, al día del censo, el efecto neto de la migración y su mortalidad en el pasado.

Respecto a la migración ocurrida durante el período interestatal, el procedimiento es similar: si denotamos con $I_{50}, E_{50}$ y $M_{50}$ la inmigración, la emigración y la migración neta acumulada a 1950 de una entidad cualquiera, y con $I_{60}, E_{60}$ y $\boldsymbol{M}_{60}$ las correspondientes a 1960, la diferencia entre la migración neta acumulada de los años 1950 y 1960 puede ser tomada como estimación de la migración neta de la entidad durante el decenio 1950-1960. En símbolos, el balance está dado por $\left(I_{60}-E_{60}\right)-\left(I_{50}-E_{50}\right)$; es decir, la migración neta intercensal se estima a través de los cambios intercensales de la migración neta acumulada.

Esta diferencia se puede expresar también de otra forma, de tal manera que haya identificación con los términos definidos de la sección primera:

$I_{60}-I_{50}$ será la inmigración intercensal $\left(I_{50-60}\right)$

$E_{60}-E_{50}$ la emigración intercensal $\left(E_{50-60}\right)$

$\left(I_{60}-I_{50}\right)-\left(E_{60}-E_{50}\right)$ la migración neta intercensal en cualquier entidad $\left(M_{50-60}\right)$

En las consideraciones anteriores se ha supuesto sólo la migración entre un estado y todos los demás. Las mismas relaciones pueden ser utilizadas cuando se trate de estimar la migración entre dos entidades del país. 


\section{imitaciones del método}

El método descrito brevemente tiene desde luego una serie de mitaciones que hay que tener en cuenta para la interpretación de los zsultados. Estas limitaciones están al margen de los errores que puea tener la información básica, que serían motivo de otro estudio. n esta sección sólo se hará mención de las limitaciones que por su ropia naturaleza tiene este método.

Para poder identificar los tipos de errores a que está sujeto el létodo, es conveniente separar las funciones que intervienen en la obención de la inmigración y la emigración y derivar a través de ellas $\imath$ expresión que se refiere a la migración intercensal.

La inmigración acumulada a 1960 de cualquier entidad es el resulado de los siguientes acontecimientos:

a) la inmigración acumulada a $1950\left(I_{50}\right)$;

b) más la inmigración intercensal $\left(I_{50-60}\right)$;

c) menos las defunciones, ocurridas durante el intervalo intercensal, de los inmigrados acumulados a $1950\left(d_{i} I_{50}\right)$;

d) menos las defunciones, ocurridas en el intervalo intercensal, de los inmigrados intercensales $\left(d_{i} I_{50-60}\right)$;

e) menos las salidas, durante el período intercensal, de los inmigrados acumulados a $1950\left(s_{i} I_{50}\right)$.

En forma simbólica la inmigración a 1960 es:

$$
I_{60}=I_{50}+I_{50-60}-d_{i} I_{50}-d_{i} I_{50-60}-s_{i} I_{50}
$$

En un análisis similar, la emigración acumulada a 1960 será igual a:

a) la emigración acumulada a $1950\left(E_{50}\right)$;

b) más la emigración interestatal $\left(E_{50-60}\right)$;

c) menos las defunciones intercensales de los emigrados acumulados a $1950\left(d_{i} \mathrm{E}_{50}\right)$;

d) menos las defunciones intercensales de los emigrados intercensales $\left(d_{i} \mathrm{E}_{50-60}\right)$;

e) menos los retornos intercensales de los emigrados acumulados a $1950\left(r_{i} E_{50}\right)$.

Esto, expresado en símbolos, es:

$$
E_{60}=E_{50}+E_{50-60}-d_{i} E_{50}-d_{i} E_{50-60}-r_{i} E_{50}
$$

Restando la expresión última de la primera y haciendo un arreglo conveniente de los términos, se tendrá:

$$
\begin{aligned}
\left(I_{60}-I_{50}\right)-\left(E_{60}-E_{50}\right)= & \left(I_{50-60}-E_{50-60}\right)-\left(d_{i} I_{50}-d_{i} E_{50}\right)- \\
& \left(d_{i} I_{50-60}-d_{i} E_{50-60}\right)-\left(s_{i} I_{50}-r_{i} E_{50}\right)
\end{aligned}
$$

En esta igualdad, la estimación correcta de la migración neta intercensal está dada por los términos $\left(I_{50-60}-E_{50-60}\right)$. Por lo tanto, la 
migración neta intercensal estimada a través de la información censa] $\left(I_{60}-I_{50}\right)-\left(E_{60}-E_{50}\right)$ está influida por los factores:

a) mortalidad: $\left(d_{i} I_{50}-d_{i} E_{50}\right)$ y $\left(d_{i} I_{50-60}-d_{i} E_{50-60}\right)$;

b) salidas y retornos: $\left(s_{i} I_{50}-r_{i} E_{50}\right)$.

Además de los efectos causados por los factores establecidos anteriormente, existen otros que deforman las estimaciones de la migración intercensal. Estas fuentes de error se refieren a los movimientos múltiples o a los circulares que no pueden ser identificados con la información censal. Si una persona se traslada de su entidad de origen y regresa a ella en el mismo decenio, ya sea directamente o después de haberse desplazado a otro estado, aparecerá, en el último censo, como persona no migrante. Del mismo modo, si ha efectuado un movimiento de su estado de origen a otra entidad y posteriormente a otra, en un mismo decenio, aparecerá como un caso de desplazamiento directo desde su estado de origen a la última entidad. Otro caso es el de las personas nacidas en una determinada entidad y enumeradas en otra en el primer censo y que durante el decenio se trasladan a una nueva entidad en donde son enumeradas por el segundo censo. Este último error no es importante si la migración neta es considerada entre un estado y el resto del país. Sin embargo, las estimaciones de la migración entre dos entidades, resultantes de la información del estado de nacimiento, deben ser interpretadas con la mayor precaución.

Poco puede hacerse para tratar de eliminar las causas de error en la estimación de la migración neta intercensal. Sólo en el caso de los errores debido al efecto de la mortalidad es posible hacer alguna corrección, y en este punto se va a centrar la atención.

\section{Consideraciones generales sobre el efecto de la mortalidad de la población migrante acumulada a 1950}

Las estimaciones de la migración intercensal obtenidas por diferencias sucesivas de los censos adolecen de una grave deficiencia: los censos contabilizan como migrantes a todas las personas que mueren durante el período intercensal pero que residían fuera de su entidad de origen. Las personas fallecidas son tratadas como "inmigrantes" en su lugar de nacimiento y como "emigrantes" desde el lugar de residencia, en el censo donde fueron enumeradas la última vez. Tales defunciones tienden a desviar apreciablemente las estimaciones de la migración intercensal, en particular muertes ocurridas en el período intercensal, de una cohorte de migrantes de avanzada edad y que han migrado muchos años antes. El monto total del error depende del tamaño de la migración acumulada al principio del decenio; a mayor volumen de la migración acumulada, mayor el error. Por lo tanto, si la migración acumulada al principio del intervalo es importante y el nivel de la mortalidad es alto, la corrección por mortalidad es absolutamente necesaria. 
La corrección efectiva de este error sólo puede efectuarse si se enen tabulaciones de la población cruzadas por entidad de nacimien, y por edad en dos censos consecutivos e índices de sobrevivencia or edad de los migrantes en el período intercensal. En muy contados aíses se han efectuado con el detalle suficiente tabulaciones por edad zgún lugar de nacimiento; no se ha hecho en México.

Al no contar con la información necesaria, se precisa adoptar algún létodo indirecto, bajo hipótesis establecidas, que sustituya al sistema atural de estimación de este fenómeno. El problema central consiste n estimar el número de sobrevivientes de la población migrante cumulada.

Para una entidad cualquiera y con relación a la inmigración, se zndrá que la inmigración intercensal es igual a la diferencia de la xmigración acumulada a 1960 y los sobrevivientes, a esa misma fecha, e la inmigración acumulada en 1950.

$$
I_{50-60}=I_{60}-S_{i} I_{50}
$$

$n$ donde $S_{i}$ es el índice de sobrevivencia intercensal de los inmigrados cumulados en 1950.

Respecto a la emigración intercensal se tendrá:

$$
E_{50-60}=E_{60}-S_{e} E_{50}
$$

!n donde $S_{e}$ es el índice de sobrevivencia intercensal de los emigrados 11950.

$\mathrm{Y}$ para la migración neta intercensal:

$$
M_{\tilde{n} 0-60}=M_{633}-S M_{\text {50 }}
$$

en doncie $S$ representa el índice de sobrevivencia en el decenio de los migrados acumulados en 1950, en el caso en que $S_{i}$ y $S_{e}$ sean iguales.

Dado que la suma de la migración neta acumulada de todas las entidades al principio $y$ al final del decenio es por necesidad igual a cero, cualquiera que sea el valor de $S$, la estimación de la migración neta intercensal total del país será también igual a cero. Resulta así de gran ventaja utilizar el mismo índice de sobrevivencia para ambos grupos, inmigrados y emigrados. Si no se hace esta hipótesis, el ajuste por mortalidad se complica aún más.

De la relación $M_{50-60}=M_{60}-S M_{50}$ se desprenden algunas consideraciones sobre la dirección en que opera el efecto de la mortalidad en la estimación de la migración neta intercensal. Este efecto depende del signo y el monto de la migración neta acumulada a $1960\left(M_{60}\right)$ y a $1950\left(M_{50}\right)$. Un resumen de esta situación se da a continuación:

1) si $M_{60}$ y $M_{50}$ son de signo opuesto, la estimación no corregida será mayor que la corregida;

2) si $M_{600}$ y $M_{50}$ son del mismo signo y el valor absoluto de $M_{60}$ es mayor que el de $M_{50}$, la estimación sin corregir será menor que la corregida. Esta situación es la normal y de aquí puede establecerse que, en general, el efecto de la mortalidad reduce la estimación de la migración neta intercensal a través de la información sobre lugar de nacimiento; 
3) si $M_{60}$ y $M_{50}$ son del mismo signo y $M_{50}$ tiene un valor absolu. to mayor que $M_{60}$, la estimación sin corregir será superior a la corregida; y

4) si $M_{60}$ y $M_{50}$ son del mismo signo y tienen valores absolutos muy parecidos, las diferencias entre la estimación corregida y la no corregida no quedan definidas e incluso pueden tener signo diferente.

Estimación de los índices de sobrevivencia intercensal de la población migrante acumulada a 1950

Como se indicó antes, el problema de la corrección por mortalidad de la migración intercensal se orienta a determinar el índice de sobrevivencia de la población migrada; esto es, debe conocerse qué proporción de los inmigrados $\left(I_{50}\right)$ y los emigrados $\left(E_{50}\right)$ acumulados a 1950 sobreviven durante los siguientes diez años.

Estas sobrevivencias están en función de sus índices de sobrevivencia por edad, así como de las estructuras por edad de la población migrada.

Para determinar el índice total de sobrevivencia de los migrados un paso previo es obtener el nivel de mortalidad en función de este mismo índice para la población total de México durante el período 19501960. Pueden seguirse varios caminos:

a) el más sencillo es relacionar la población de 10 y más años censada en 1960 con la población total censada en 1950. Este índice representa la proporción de personas presentes en 1950 y que sobrevivieron a 1960 , en el supuesto de que no haya habido migración internacional significativa y que los dos censos tengan igual grado de exactitud;

b) la población censada en 1950 se proyecta a 1960 utilizando las relaciones decenales de sobrevivencia por edad de la tabla de mortalidad para el total de México, 1950-1960, y se mide la relación entre la población de 10 y más años esperada en 1960 y la población total censada en 1950 ;

c) se proyecta a 1960 la población por grupos de edad censada en 1950 (corregida por subenumeración de la población de 0 a 4 años) mediante las relaciones de sobrevivencia decenal de la tabla de vida nacional en 1950-1960. Se mide la relación entre la población de más de 10 años esperada a 1960 y la población de 1950 corregida por subenumeración de 0-4 años; 5

d) se proyecta a 1960 la población por grupos de edad censada en 1950 (corregida por subenumeración de 0 a 4 años) ${ }^{6}$ de cada una de las entidades federativas, mediante las relaciones de cuatro tablas de mortalidad regionales, 1950-1960, que agrupan la experiencia en mortalidad de las entidades que tengan

5 Se sigue el procedimiento del diagrama de Lexis, utilizando los nacimientos y defunciones por edad registrados en el período 1945-1950.

6 Véase la nota 5. 
índices económicos y sociales parecidos. ${ }^{7}$ En este caso se obtienen índices de sobrevivencia de cada una de las entidades efectuando las relaciones usuales. Mediante la relación de la suma de las poblaciones estatales de 10 y más años esperadas a 1960 y la población censada en 1950, corregida por subenumeración de 0-4 años, se obtiene el índice de sobrevivencia del total del país.

Los resultados de estos cálculos (cuadro 1 ) no difieren mucho, siendo el más alto el estimado a través de las informaciones censales. La diferencia entre el valor mínimo (.9114) y el máximo (.9239) no es de más de $1.3 \%$. En esta forma puede seleccionarse cualquiera de ellos para representar el índice cie sobrevivencia de la población total durante 1950-1960.

\section{Cuadro 1}

MÉxico: INDICES DE SOBREvIVENCIA INTERCENSAL DE LA POBLACIÓN TOTAL, 1950-1960, ESTIMADOS CON DIFERENTES ELEMENTOS

Números absolutos

Indice de sobrevivencia

a) Población total censada en 1950 y población de más de 10 años censada en 1960

$23829338 / 25791017$ .9239

b) Población por grupos de edad censada en 1950 y relaciones de sobrevivencia de la tabla de vida nacional, 1950-1960

$23537103 / 25791017$

.9126

c) Población por grupos de edad censada en 1950 (corregida por subenumeración en 0-4 años) y relaciones de sobrevivencia de la tabla de vida nacional, 1950-1960

$24090060 / 26433144$ .9114

d) Población por grupos de edad de las entidades censadas en 1950 (corregidas por subenumeración en $0-4$ años) y relaciones de sobrevivencia de las tablas de vida estatal, 1950-1960

7 Los cuatro grupos de entidades que se formaron y sus respectivas tablas de mortalidad son los mismos que aparecen en el trabajo de Raúl Benítez Zenteno y Gustavo Cabrera, Proyecciones de la población de México, 1960-1980, Banco de México, México, 1966, pp. 88-97. 
Se ha escogido el índice obtenido mediante las estimaciones de la población a 1960 , utilizando las tablas de mortalidad regional, debido a que un subproducto importante son los índices de sobrevivencia intercensal para cada una de las entidades y que se utilizan más adelante. En conclusión, se adopta un índice de sobrevivencia intercensal de la población total de México de .9128 .

El segundo paso es determinar si este índice representa la mortalidad intercensal de la población migrante acumulada a 1950. En caso de que no lo represente, se deberá a las siguientes situaciones: a) que los migrantes tienen un patrón de mortalidad diferente al de la población total; $b$ ) que los migrantes tienen una distribución por edad diferente a la distribución de la población total del país.

Estos dos factores son importantes, pero se considera de mayor significación el segundo. De ninguno de ellos se tiene información directa y sólo del segundo, a través de comparaciones y estableciendo algunas hipótesis, puede normarse un criterio acerca de su comportamiento.

Por lo que respecta al primer factor, en donde no hay elemento indicador del sentido de la mortalidad diferencial entre los migrantes y los no migrantes, y pensando que este margen pudiera no ser significativo, la solución práctica es suponer que el esquema de la mortalidad específica por edad de los migrantes es igual al de los no migrantes.

Al factor de la estructura por edad de la población migrante puede dársele un tratamiento diferente. Es reconocido que la migración es de orden selectivo, es decir, que las características demográficas, sociales y económicas de los migrantes difieren de las de los no migrantes. Entre estas características se encuentra la estructura por edad. La distribución por edad diferencial de los migrantes afecta su índice total de sobrevivencia debido a la mortalidad diferencial por edad. Si la estructura de los migrantes fuera igual a la de la población total, el índice de sobrevivencia sería el mismo; si fuera más joven, el índice de los migrantes sería mayor; y si más vieja, menor.

Al no contarse con ninguna indicación sobre esta característica diferencial, se ha recurrido a la experiencia de otros países que tabulan la información requerida; es decir, la estructura por edad de los migrantes. El objetivo final es poder determinar, a través de las estructuras por edad de la población migrante y de la total, las diferencias que existen en los índices de sobrevivencia de esos dos tipos de poblaciones.

Entre los pocos países que tabulan la población migrante por edad se encuentra Venezuela, que desde el censo de 1940 viene preparando esta información. Con los datos de 1940, 1950 y 1960, se estimó el índice de sobrevivencia de la población total de Venezuela y de la población migrante. El procedimiento fue el siguiente:

1) la población total de Venezuela censada en esos años se distribuyó de acuerdo con los mismos grupos de edad en que estaba presentada la población migrante;

2) se proyectaron diez años las poblaciones totales de 1940, 1950 y 1960 por edad, mediante la aplicación de los índices de sobre. 
vivencia por edades de las tablas de vida de México. El índice de sobrevivencia de la población total de Venezuela se obtuvo relacionando la población proyectada de 10 y más años con la población total censada diez años antes; y

3) la población migrante por grupos de edad de los mismos censos fue también proyectada diez años aplicándole los mismos índices de sobrevivencia por edad del punto anterior. Se relacionó la población migrante de 10 años y más de edad y la población inicial, obteniéndose los respectivos índices de sobrevivencia.

Con objeto de apreciar la influencia de la estructura por edad en el índice de sobrevivencia de los migrantes, se efectuó el mismo cómputo con los migrantes extranjeros que residían en Venezuela en esos mismos años. Esto mismo se hizo con la población total y la nacida en el exterior de los Estados Unidos en los años 1880, 1890, 1900 y 1920, período en que la inmigración internacional a ese país fue muy intensa. No obstante que los patrones de la migración internacional difieren de los de la migración interna, su observación es útil para poder precisar los límites entre los cuales varían los índices de sobrevivencia de los migrantes internacionales y de la población total.

El procedimiento fue igual al, explicado en los puntos anteriores, siendo también utilizadas las relaciones de sobrevivencia por grupos de edad de la tabla de vida de México de 1950 a 1960.

Los resultados se presentan en el cuadro 2, en donde se han relacionado los índices de sobrevivencia de la población total con los de la población migrante (interna o extranjera) en diferentes intervalos de tiempo.

\section{Cuadro 2}

Índices de sobrevivencta de Venezuela y Estados Unidos EN DIVERSOS PERÍODOS

\begin{tabular}{|c|c|c|c|c|}
\hline Pa 1 a & \multicolumn{4}{|c|}{ Indices de sobrevivencia 9} \\
\hline Venezuela & $1940-1950$ & $1950-1960$ & $1960-1970$ & \\
\hline Población total $\left(S_{t}\right)$ & .9114 & .9115 & .9047 & \\
\hline Población migrante $\left(S_{m}\right)$ & .8985 & .8926 & .8812 & \\
\hline Población extranjera $\left(s_{e}\right)$ & .8524 & .8935 & .8960 & \\
\hline$s_{t} / s_{m}$ & 1.01 & 1.02 & 1.03 & \\
\hline$s_{t} / s_{e}$ & 1.07 & 1.02 & 1.01 & \\
\hline Estad08 Unidos & $1880-1890$ & $1890-1900$ & $1900-1910$ & $1910-1920$ \\
\hline Población total $\left(S_{t}\right)$ & .9030 & .8994 & .8966 & .8929 \\
\hline Población extranjera $\left(S_{\theta}\right)$ & .8414 & .8406 & .8309 & .8415 \\
\hline$s_{t} / s_{e}$ & 1.07 & 1.07 & 1.08 & 1.06 \\
\hline
\end{tabular}

a A los diferentes tipos de población se aplicaron las relaciones de sobrevivencia decenales de la tabla de vida de México, 1950-1960. 
De las relaciones entre los índices de la población total $\left(S_{t}\right)$ y los de la población migrante $\left(S_{m}\right)$ de Venezuela, se observa que los primeros son superiores por un margen reducido de $1 \%$ en el primer decenio y $3 \%$ en el último. Esta consideración puede indicar que las estructuras por edad de los migrantes y de la población total no difieren significativamente, ya que sus índices de sobrevivencia son muy semejantes.

En cuanto a la relación con la población extranjera $\left(S_{e}\right)$ de Venezuela, el primer decenio revela un índice de población superior en $7 \%$, que disminuye fuertemente en los siguientes intervalos. Esta disminución parece indicar que los patrones y el volumen de la inmigración internacional antes de 1940 fueron muy diferentes a los posteriores a ese tiempo. Las estadísticas muestran que la migración internacional acumulada hasta el año de 1940 fue de sólo 48000 personas, pero que se incrementó a 195000 y 500000 personas en 1950 y 1960, respectivamente. Estas fuertes corrientes migratorias del exterior cambiaron posiblemente la estructura de la población extranjera ya existente, rejuveneciéndola.

Por último, las diferencias en los índices de sobrevivencia de la población total de Estados Unidos y la población extranjera se mantuvieron constantes en las diversas décadas, siendo superior en un $7 \%$ el índice de la población total. Esto podría significar que la estructura por edades de ambas poblaciones cambió en el mismo sentido.

De estas breves consideraciones puede concluirse que los índices de sobrevivencia de la población total son superiores a los de la población migrante entre un $3 \%$ y un $8 \%$, tomando los valores máximos que se observan en la población migrante de Venezuela y la población extranjera de Estados Unidos. Estas diferencias se deben, en todos los casos, a la diferente estructura por edad de las poblaciones consideradas, debido a que les fue aplicado el mismo esquema de mortalidad específica por edad.

En el supuesto de que las relaciones máximas entre la sobrevivencia decenal de la población total y la correspondiente de la población migrante, observadas en Venezuela y Estados Unidos, operaran en los índices respectivos de México, sería posible estimar el valor de la sobrevivencia decenal de su población migrante. Es decir, cumpliéndose las igualdades $1.03=S_{M} / S_{m}^{\prime}$ y $1.08=S_{M} / S^{\prime \prime}{ }_{m}$, siendo $S_{M}$ el índice de sobrevivencia de la población total de México y $S_{m}^{\prime}$ y $S^{\prime \prime}{ }_{m}$ el de la población migrante (según el valor que se adopte), estos últimos podrán ser estimados en función del valor conocido de $S_{M}(.9128)$. De esta forma se tendrá que:

$$
S_{m}^{\prime}=.9128 / 1.03 \text { y } S_{m}^{\prime \prime}=.9128 / 1.08
$$

lo que da como resultado que el índice de sobrevivencia decenal de los migrantes tome los valores-límite máximos de .8862 ó .8451 .

El supuesto que se ha hecho sobre la adopción para México de Ias relaciones que se dan en Venezuela y Estados Unidos entre los respectivos índices de sobrevivencia abarca las siguientes situaciones:

a) que el esquema de la mortalidad específica por edad de los migrantes sea el mismo que para la población total, y 
b) que el efecto de la estructura de los migrantes sobre el índice de sobrevivencia de los dos países se presente con la misma intensidad en la sobrevivencia de los migrantes de México.

En resumen, los índices de sobrevivencia de la población migrante de México pueden tomar diferentes valores según la hipótesis que se establezca sobre su estructura por edad:

a) la sobrevivencia decenal de los migrantes es igual a la de la población total en el caso de que sus estructuras sean las mismas. Este valor es de .9128;

b) el índice será .8862 si se da en México la relación entre el índice de sobrevivencia de la población total y el de la población migrante de Venezuela (1.03);

c) el índice será de .8451 si se mantiene la relación entre el índice de la población total y la extranjera de Estados Uni$\operatorname{dos}(1.08)$.

Como se señaló en las secciones anteriores, la corrección que se haga a la migración neta intercensal por el efecto de la mortalidad de los migrantes acumulados, ocurrida en el decenio, depende del nivel del índice de sobrevivencia y de los volúmenes de la migración neta acumulada al principio y al final de la década. Los censos de 1950 y 1960 reportaron que se encontraban residiendo fuera de su entidad de nacimiento 3306000 y 5200000 personas, respectivamente, en esos años. Aplicando a estas cifras los tres índices de sobrevivencia propuestos anteriormente, los resultados de la estimación de la migración neta intercensal, 1950-1960, serían los siguientes:

a) con el índice de sobrevivencia de la población total de México: $M_{50-60}=5.200-(.9128) 3.306=2.183$ millones;

b) con el índice de sobrevivencia corregido por la experiencia de Venezuela: $M_{50-60}=5.200-(.8862) 3.306=2.271$ millones;

c) con el índice de sobrevivencia corregido por la experiencia de Estados Unidos: $M_{50-60}=5.200-(.8451) 3.306=2.406 \mathrm{mi}-$ llones.

Las diferencias absolutas con relación a la primera estimación son de 88000 y 223000 personas, respectivamente. En números relativos, estas diferencias representan $4.0 \%$ y $10.2 \%$. Como ya se vio, estos índices son el resultado de la utilización de las relaciones máximas dadas en Venezuela y Estados Unidos. Si se consideran las relaciones mínimas tanto para la población migrante como para la extranjera de Venezuela, las correcciones tendrían un efecto muy reducido (las diferencias de los índices de sobrevivencia son del $1 \%$ para ambos tipos de población). (Véase el cuadro 2.)

El índice que parece más propio aplicar es el que resulta de las relaciones de Venezuela de acuerdo con la migración interna. Las características demográficas de Venezuela son parecidas a las de México. El intenso proceso de urbanización que se ha dado en Venezuela en los últimos decenios se ha experimentado también en México. Tal vez 
las motivaciones de la población de ambos países para cambiar de lugar de residencia tengan alto grado de similitud, así como también el patrón de migración por edad en los últimos decenios puede haber sido semejante. Estas simples consideraciones hacen pensar que la adopción de la proporcionalidad que se da en los índices de sobrevivencia en Venezuela sea la más adecuada para México.

\section{Mortalidad regional en México}

En todos los países se encuentran niveles de mortalidad diferencial por región más o menos acentuados. Por ejemplo, en Estados Unidos se han encontrado marcadas diferencias entre sus entidades; Dorn 8 estimó que en 1950, después de ajustar las diferencias debidas a las estructuras por edad, existían diferencias del $40 \%$ entre la tasa de mortalidad más alta y la más baja de los 48 estados.

En México se observan fuertes contrastes en los niveles de mortalidad por regiones, aun cuando en los últimos decenios sus diferenciales han disminuido con el descenso pronunciado de la mortalidad total. Sin embargo, en las estimaciones de la migración por entidad la aplicación indiscriminada del índice de sobrevivencia nacional puede tener influencia apreciable, siendo mayor el error cuanto más elevado sea el nivel de la mortalidad.

Los niveles diferenciales de la mortalidad por regiones pueden apreciarse a través de la esperanza de vida. Se han calculado en cuatro zonas del país en que se han agrupado las entidades que presentan características económicas y sociales semejantes. ${ }^{9}$ Las esperanzas de vida al nacimiento, de las cuatro regiones que agrupan a las 32 entidades, se muestran en el cuadro 3.

\section{Cuadro 3}

MÉXICO: EsPeranZaS DE VIDA DEL PERÍODO 1950-1960, POR REGIONES

\begin{tabular}{|c|c|c|}
\hline & Entidades & $e_{0}^{0}$ \\
\hline
\end{tabular}

Región 1. Baja California Norte, Distrito Federal, Nuevo León, Sinaloa y Tamaulipas

Región 2. Baja California Sur, Coahuila, Chihuahua, Durango y Sonora

Región 3. Aguascalientes, Campeche, Colima, Guanajuato, Jalisco, Michoacán, Morelos, Nayarit, Quintana Roo, Querétaro, San Luis Potosí, Tabasco, Veracruz, Yucatán y Zacatecas

Región 4. Chiapas, Hidalgo, Guerrero, México, Oaxaca, Puebla y Tlaxcala

Nivel nacional

8 Harold F. Dorn, "Mortality", en Philip M. Hauser y Otis D. Duncan, compiladores, The Study of Population, Chicago, University of Chicago Press, 1959.

9 Benítez Zenteno y Cabrera, op. cit., pp. 87-89. 
De las cifras presentadas, puede verse que la diferencia entre el valor máximo y el mínimo de la esperanza de vida es de 13.05 años, lo que da una idea clara del diferente comportamiento de la mortalidad regional en México.JDe utilizarse el nivel de la sobrevivencia nacional, se sobrestimarían los volúmenes de la migración neta intercensal de las entidades agrupadas en las regiones 1 y 2, las entidades de la región 3 no tendrían diferencia significativa, y las de la región 4 se subestimarían.

En el punto anterior se ha considerado sólo la estimación del índice de sobrevivencia del total de la población migrante, sin referencia a la composición de la mortalidad regional. En realidad, el proceso natural sería establecer los índices de sobrevivencia de los migrantes en cada una de las entidades, teniendo en cuenta el nivel de mortalidad propio y las respectivas estructuras por edad, para derivar de las estimaciones de la migración neta intercensal de cada una de ellas el volumen de la migración intercensal total del país. Este proceso complicaría demasiado los cálculos, a más de que sería casi imposible llevarlo a cabo por la carencia de información. Por otro lado, sería difícil asimilar los patrones de migración regionales por edad que se dan, por ejemplo, en Venezuela. Para hacerlo habría necesidad de identificar regiones de Venezuela y México que tuvieran comportamientos semejantes debido a iguales condiciones demográficas, económicas y sociales. En el caso del total del país, pueden establecerse estas semejanzas debido a que se trata, en general, de situaciones prevalecientes en todo el territorio, pero esto no significa que dichas características se den también a nivel regional. En algunos casos es posible pensar que haya similitud en el proceso de migración, como puede ser en las entidades en que se localizan las capitales de ambos países. Las ciudades de Caracas y México absorben proporciones muy elevadas de la migración, en parte por el centralismo económico, político, educativo, etc. En el resto del país, el proceso de migración puede obedecer a muy diferentes razones.

No disponiéndose de una solución que concilie las diversas situaciones que intervienen en la estimación de la sobrevivencia de los migrantes de las entidades, un camino práctico que puede seguirse consiste en aplicar el valor de la relación que se usó en la estimación de la sobrevivencia intercensal de la población migrante del total del país (1.03) al índice de sobrevivencia de la población total de cada entidad, bajo estos dos supuestos:

a) que la población migrante acumulada a 1950 haya asimilado el esquema de la mortalidad específica por edad de la población total que reside en la entidad de llegada. En realidad, este supuesto está considerado implícitamente al estimar el indice de sobrevivencia intercensal de la población total migrante, ya que la corrección se hace con base en el índice de la población total obtenido a través de las sobrevivencias por edad de cada entidad (véase p. 323 , inciso $d$ );

$b$ ) que la diferencia porcentual entre los índices de sobrevivencia de la población total y la migrante, que fue de $3 \%$, se conserve en las entidades; es decir, que $1.03=S_{t}^{E} / S_{m}^{E}$ en cada en- 
tidad, en donde $S_{t}^{B}$ representa el índice de sobrevivencia intercensal de la población total por entidad y $S_{m}^{E}$ el índice de sobrevivencia de los migrantes que se quiere estimar, ambos de una entidad en particular.

De la anterior relación se obtiene la estimación de la sobrevivencia intercensal de los migrantes de cada una de las entidades, mediante la expresión $S_{m}^{L^{*}}=S_{t}^{t} / 1.03$, en donde $S_{t}^{E}$ toma los valores que se dan en el cuadro 4.

\section{Mortalidad de los migrantes intercensales, 1950-1960}

Por último, es necesario considerar la mortalidad que experimenten, durante el decenio de estudio, los migrantes que llegaron a las entidades en el período intercensal y que murieron antes de que fueran enumerados en el último censo, habiéndolo sido en el primero en su entidad de origen. Estas defunciones hacen disminuir el volumen de la migración neta intercensal.

Mediante la corrección de la mortalidad intercensal de la migración neta aculada a 1950, se obtienen los sobrevivientes en 1960 de los migrantes que se desplazan en el decenio sin tocar el efecto de su propia mortalidad. La sobrevivencia de este tipo de población es también función de la mortalidad específica por edad y de la estructura por edad de los migrantes intercensales.

En lo que se refiere a la estructura, en el proceso migratorio hay que distinguir claramente dos situaciones: aquella que se refiere a los movimientos efectuados sin especificación de período de tiempo y que se ha llamado migración neta acumulada, y los movimientos que están comprendidos dentro de un intervalo de tiempo establecido, en el caso estudiado el período intercensal. Las características de la estructura por edad de estos dos grupos de población pueden ser muy ciferentes y de hecho lo son; los migrantes de la primera categoría han estado sujetos a un mayor tiempo de envejecimiento, mientras que los de la segunda categoría han envejecido como máximo diez años. Si se supone que los patrones por edad de los migrantes no han cambiado con el tiempo, es decir, si la incidencia de la migración por edad se ha mantenido constante durante el tiempo, la estructura por edad de los migrantes acumulados a una fecha estará más envejecida que la estructura de los migrantes intercensales a la misma fecha. En el caso de que los patrones de edad varíen en forma acusada, no se puede concluir la naturaleza de las estructuras.

Suponiendo que las estructuras de los migrantes se hayan conservado aproximadamente con el tiempo y tomando como base la experiencia de Venezuela, adaptada a México, en donde la estructura por edad de la población migrante acumulada resultó ser ligeramente menos joven que la de la población total, pođría pensarse que la población migrante intercensal tuviera una estructura más joven, o cuando menos igual, a la de la población total. 


\section{Cuadro 4}

MÉXICO: INDICES DE SOBREVIVENCIA DE LA POBLACIÓN TOTAL, DE LA POBLACION MIGRANTE ACUMULADA A 1950 Y DE LOS MIGRANTES

INTERCENSALES, 1950-1960, DE LAS ENTIDADES FEDERATIVAS

\begin{tabular}{|c|c|c|c|c|c|}
\hline \multirow[b]{2}{*}{ Entidad federativa } & \multirow[b]{2}{*}{$\begin{array}{c}\begin{array}{c}\text { Población } \\
\text { total }^{\mathrm{a}}\end{array} \\
p_{0 y+}^{50} \\
\text { (En miles) }\end{array}$} & \multirow[b]{2}{*}{$\begin{array}{c}\text { Población } \\
\text { en } 1960 \mathrm{~b} \\
P_{10 y+}^{60} \\
\text { (En miles) }\end{array}$} & \multicolumn{3}{|c|}{ Indices de sobrevivencia } \\
\hline & & & $\begin{array}{c}\text { Población } \\
\text { total c } \\
{ }_{10} S_{t}^{E}\end{array}$ & $\begin{array}{c}\text { Migrantes } \\
\text { acumula- } \\
\text { dos d } \\
{ }_{10} S_{m}^{E}\end{array}$ & $\begin{array}{c}\text { Migrantes } \\
\text { intercen- } \\
\text { sales } \\
{ }_{5} S_{m}^{E}\end{array}$ \\
\hline 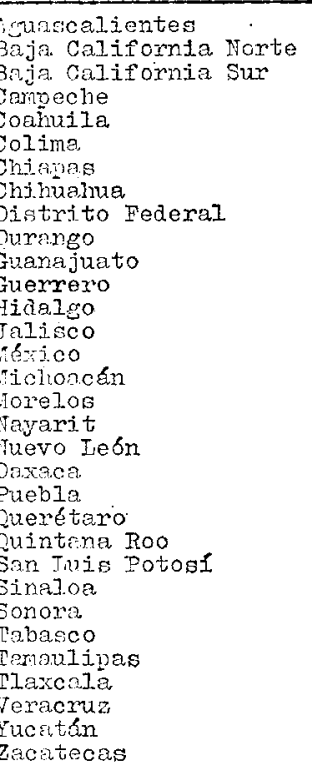 & $\begin{array}{r}194.5 \\
223.4 \\
62.9 \\
127.1 \\
757.2 \\
115.3 \\
907.5 \\
856.4 \\
3058.2 \\
661.4 \\
1391.2 \\
943.6 \\
858.6 \\
1808.7 \\
1133.2 \\
1486.6 \\
282.2 \\
301.3 \\
765.8 \\
1440.0 \\
1643.3 \\
298.2 \\
27.1 \\
895.7 \\
652.4 \\
533.5 \\
365.8 \\
734.4 \\
292.9 \\
2069.0 \\
532.1 \\
703.6\end{array}$ & $\begin{array}{r}177.6 \\
212.4 \\
58.6 \\
116.5 \\
700.8 \\
105.2 \\
813.4 \\
705.4 \\
2846.4 \\
613.6 \\
1268.2 \\
864.0 \\
763.4 \\
1647.2 \\
1172.4 \\
1361.6 \\
257.4 \\
275.4 \\
713.3 \\
1282.2 \\
1460.9 \\
272.3 \\
25.9 \\
819.4 \\
609.1 \\
495.2 \\
336.3 \\
695.7 \\
260.7 \\
1892.6 \\
483.4 \\
644.1\end{array}$ & $\begin{array}{l}.9131 \\
.9299 \\
.9316 \\
.9166 \\
.9255 \\
.0124 \\
.8963 \\
.9288 \\
.9307 \\
.9277 \\
.9115 \\
.9156 \\
.8891 \\
.0107 \\
.8878 \\
.9159 \\
.9121 \\
.9140 \\
.9314 \\
.0904 \\
.0863 \\
.9131 \\
.9557 \\
.9137 \\
.9336 \\
.9232 \\
.9194 \\
.9337 \\
.8901 \\
.9147 \\
.9085 \\
.9154\end{array}$ & $\begin{array}{l}.8865 \\
.9028 \\
.9048 \\
.8999 \\
.8986 \\
.8858 \\
.8702 \\
.9018 \\
.9036 \\
.9007 \\
.8851 \\
.8890 \\
.8632 \\
.8842 \\
.8620 \\
.8892 \\
.8855 \\
.8374 \\
.9043 \\
.8645 \\
.8505 \\
.8865 \\
.9279 \\
.8371 \\
.9064 \\
.9012 \\
.0026 \\
.9065 \\
.8642 \\
.8691 \\
.8821 \\
.8888\end{array}$ & 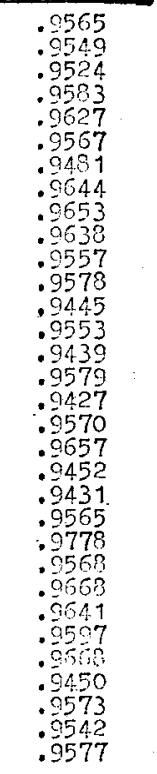 \\
\hline oten 1 & $26 \quad 433.1$ & 24129.6 & .9128 & .8862 & .9564 \\
\hline
\end{tabular}

a Población censada en 1950, corregida por subenumeración en el grupo de edad de 0 a 4 años.

b Población esperada a 1960 de 10 y más años de edad, obtenida aplicando a la población de 1950 corregida de cada entidad las relaciones de sobrevivencia por grupos de edad de la tabla de vida de cuatro zonas de México, 1950-1960.

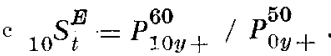

$$
\begin{aligned}
& { }_{10} S_{m}^{E}={ }_{10} S_{t}^{E} / 1.03 \text {. } \\
& \text { e }{ }_{5} S_{m}^{E}=.5+{ }^{1 / 2}{ }_{10} S_{t}^{E} \text {. }
\end{aligned}
$$


Si estas estructuras fueran iguales, el índice de sobrevivencia sería el mismo en las dos poblaciones, es decir, .9128 (suponiendo el mismo esquema de mortalidad específica por edad en las dos poblaciones). Este valor se considera como el mínimo. Por otro lado, si la población migrante tuviera una estructura más joven que la total, el nivel más alto de su índice de sobrevivencia decenal sería .9736, valor máximo que se da en las tablas de vida de México, 1950-1960, y que corresponde al grupo de edad de 5-9 años. Esta sobrevivencia supondría que la población migrante estuviera concentrada, al principio del decenio, en ese grupo de edad. La diferencia entre el valor máximo y el mínimo (.9736 y .9128) es del $6.6 \%$.

Cualquier elección de una sobrevivencia entre estos límites sería arbitraria. Sin embargo, se puede pensar que el valor del índice se aproxima mucho más al mínimo que al máximo. Esta observación se basa en que, siendo la estructura de la población migrante acumulàda ligeramente más vieja que la total, la diferencia entre los respectivos índices es de sólo $3 \%$, por lo que sería difícil que la población migrante intercensal, que se supuso tiene estructura más joven que la acumulada, tuviera un impacto tan fuerte en el nivel de sobrevivencia como para incrementarlo hasta el valor de .9736 (valor máximo), que es $10 \%$ superior al de la sobrevivencia acumulada (.8862). El efecto podría ser, por ejemplo, de un $3 \%$ mayor que la acumulada, resultando la misma sobrevivencia que la de la población total (.9128); o bien las diferencias serían un poco mayores, obteniéndose un índice un poco superior a] de la población total.

Sólo para tener una aproximación del monto de la migración intercensal sin la disminución representada por las muertes de los migrantes intercensales, se ha adoptado el mismo nivel de sobrevivencia que corresponde a la población total, es decir, .9128; en consecuencia, si se quieren tomar en cuenta los diferenciales de mortalidad por entidad, los índices de sobrevivencia serán los de la población total de cada entidad (véase el cuadro 4). Esta elección supone las mismas hipótesis que se consideraron en la mortalidad de la población migrante acumulada: la mortalidad específica por edad es la misma en la población inmigrante y la emigrante en el decenio; igual también será la mortalidad específica de la población total de las entidades y la de los migrantes intercensales de la misma entidad.

El monto de la corrección total puede estimarse mediante el rejuvenecimiento de los migrantes intercensales corregidos por mortalidad:

$$
M_{50-60}^{\prime}=\frac{M_{60}-{ }_{10} S_{m}^{E} \cdot M_{50}}{.5+1 / 2{ }_{10} S_{t}^{E}}
$$

donde $M^{\prime}{ }^{\circ 0-60}$ es la migración neta intercensal corregida tanto por la mortalidad intercensal de los migrantes acumulados a 1950 como por la mortalidad de los migrantes intercensales durante el decenio; $M_{60}$ y $M_{50}$ son la migración acumulada a 1960 y 1950 , respectivamente y ${ }_{10} S_{m}^{E}$ y ${ }_{10} S_{t}^{E}$ son los índices de sobrevivencia decenal de la población migrante acumulada a 1950 y de la población total de la entidad. 
Para aplicar la expresión antericr puede suponerse que los migran. tes se desplazan uniformemente durante el decenio. En esta forma se tendrá que, en promedio, la población migrante que llega estará expuesta al riesgo de morir durante sólo cinco años. Una aproximación de la sobrevivencia para un período de cinco años, en función del índice que se tiene y que abarca 10 años, es: ${ }_{2} S_{m}^{E}=.5+1 / 2{ }_{10} S_{t}^{E}$. (Los resultados de este cálculo se dan en el cuadro 4.$)$

El valor de $M^{\prime}{ }_{50-60}$ será :

$$
M_{50-60}^{\prime}=\frac{5.200-(.8862) 3.306}{.5+1 / 2(.9128)}=\frac{2.271}{.9564}=2.374 \text { millones. }
$$

Los montos y las tasas de las diversas estimaciones de la migración neta intercensal en 1950-1960 se resumen en el cuadro 5.

\section{Cuadro 5}

México: Resultados de las diferentes estimaciones de la migractón NETA INTERCENSAL, 1950-1960

\begin{tabular}{|c|c|c|c|c|c|c|}
\hline \multirow[b]{3}{*}{$\begin{array}{l}\text { Estima- } \\
\text { cton }\end{array}$} & \multirow[b]{3}{*}{$\begin{array}{c}\text { Monto } \\
\text { (en miles) }\end{array}$} & \multicolumn{4}{|c|}{ Diferencias } & \multirow{3}{*}{$\begin{array}{l}\text { Tasa por- } \\
\text { centual de } \\
\text { migración } \\
\text { neta inter- } \\
\text { censal }\end{array}$} \\
\hline & & \multicolumn{2}{|c|}{ Absolutas } & \multicolumn{2}{|c|}{ En porciento } & \\
\hline & & $\begin{array}{l}\text { respecto } \\
a \mathrm{M}\end{array}$ & $\begin{array}{l}\text { respecto } \\
\quad \text { a } \mathrm{M}^{1}\end{array}$ & $\begin{array}{c}\text { respecto } \\
\text { a } \mathrm{M}\end{array}$ & $\begin{array}{c}\text { respecto } \\
\text { a } \mathrm{M}^{1}\end{array}$ & \\
\hline$M_{-(i)-60}$ & 1894 & - & - & - & - & 6.3 \\
\hline$M_{i(1)-(; ;)}^{1}$ & 2271 & 377 & - & 19.9 & - & 7.6 \\
\hline$M_{5,10-1 ; 0)}^{2}$ & 2374 & 480 & 103 & 25.7 & 4.5 & 7.9 \\
\hline
\end{tabular}

a Estimación sin ninguna corrección $(5.200-3.306)$.

b Corregida por la mortalidad intercensal de los migrantes acumulados a 1950 $(5.200-(.8862) 3.306$.

c Corregida por la mortalidad intercensal de los migrantes acumulados a 1950 y por la mortalidad intercensal de los migrantes intercensales,

$$
\frac{5.200-(.8862) 3.306}{.5+1 / 2(.9128)}
$$

a Se relacionó el monto con la población nativa total a mitad del periodo.

La corrección total de la migración intercensal representa un aumento global del $25 \%$; la estimación tomando sólo la mortalidad de los migrantes acumulados es superior en un $20 \%$ a la no corregida. Las tasas de migración neta intercensal indican que de cada 100 personas, 8 dejaron su entidad de nacimiento durante el decenio 1950-1960. El número estimado de sobrevivientes en 1960 de los migrantes intercensales es de 2271000.7 
Resultados de la migración neta intercensal estimada con información censal

Con la metodología descrita anteriormente, se han estimado los volúmenes migratorios por entidad federativa, comparando sus montos corregidos y no corregidos por mortalidad. Los resultados aparecen en el cuadro 6 .

En primer término, se observa que en casi todas las entidades, el monto corregido de la migración intercensal fue superior al no corregido. Solamente en los estados de Coahuila, México y Nayarit la mortalidad redujo el volumen migratorio no corregido. La disminución se explica por el hecho de que en Coahuila, el balance de su migración acumulada a 1950 fue positivo, mientras que el de 1960 fue negativo. Esta diferencia de signos en el saldo migratorio en esos años produjo el efecto de que la migración intercensal sin corregir esté sobrestimada. Por lo que toca a los estados de México y Nayarit, el monto de la migración intercensal sin corregir fue mayor que el corregido debido a que el balance de los migrantes en 1950 fue superior al de 1960 teniendo iguales signos en sus saldos.

En cuanto a la comparación entre los montos de la migración intercensal resultantes de la aplicación de diferentes índices de sobrevivencia, se puede apreciar que no difieren significativamente cuando sólo se utiliza la sobrevivencia de los migrantes de la propia entidad (cuadro 6 , columnas 3 y 4). Una situación semejante se refleja en los re sultados de la migración cuando se corrige por la mortalidad de lós migrantes intercensales; las diferencias que hay con el volumen de los migrantes sin este tipo de corrección no son significativas en ninguna entidad (cuadro 6, columnas 4 y 5 ).

De los anteriores comentarios puede concluirse que, en general, las estimaciones de la migración intercensal de las entidades son satisfactorias cuando se corrigen por el efecto de la mortalidad con el índice de sobrevivencia de la población migrante de todo el país, sin tomar en cuenta la mortalidad diferencial de las entidades. Esto puede ser cierto cuando la mortalidad de todo el país se encuentre a un nivel relativamente bajo, como sucede en México.

\section{ESTIMACIÓN dE La MIGRación INTERNa MEDIANTE ÍNDICES DE SOBRE- VIVENCIA}

Para la medición de la migración interna a través de métodos indirectos, el material estadístico más importante que puede ser usado son las distribuciones por edad de la población obtenidas en los censos. La técnica para estimar la migración neta en función de los efectivos de la población por edad en dos censos consecutivos es conocida como el método de las tasas de sobrevivencia.

La lógica sobre la cual está basado el procedimiento es la siguiente :

Si los residentes de una comunidad, entidad o región fueron enumerados en un censo, cada uno a su edad $x$, y si ninguna persona migró, ya sea hacia o desde la comunidad, la población enumerada 


\author{
Cuadro 6 \\ MéXico: Migración Neta intercensal, 1950-1960 \\ (En miles)
}

\begin{tabular}{|c|c|c|c|c|}
\hline $\begin{array}{l}\text { Intidad federativa } \\
\text { (1) }\end{array}$ & $\begin{array}{l}\text { Estimacion } \\
\text { sin corre- } \\
\text { gir a } \\
\text { I } 50-60 \\
\text { (2) }\end{array}$ & $\begin{array}{l}\text { Estimao } \\
\frac{\text { morte }}{b} \\
1: 50-60 \\
(3)\end{array}$ & $\begin{array}{l}\text { nes cor } \\
\text { dad int } \\
\frac{c}{50-60} \\
(4)\end{array}$ & $\begin{array}{l}\text { dansal } \\
\text { ensar } \\
50-60 \\
(5)\end{array}$ \\
\hline 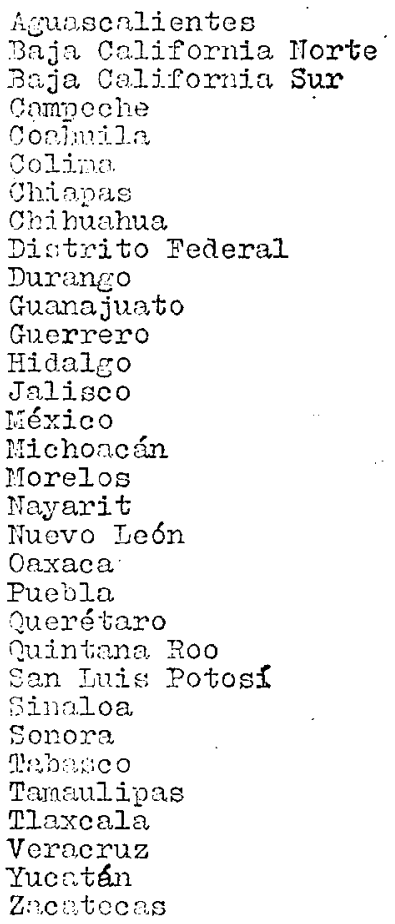 & 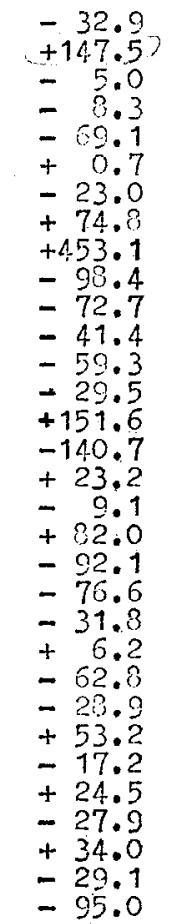 & 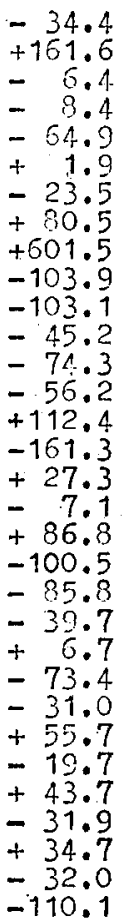 & $\begin{array}{l}-33.6 \\
+161.2 \\
-\quad 6.0 \\
-\quad 3.5 \\
-64.0 \\
+\quad 2.2 \\
-23.7 \\
+80.9 \\
+593.3 \\
-102.0 \\
-101.9 \\
-44.7 \\
-76.3 \\
-54.5 \\
+106.3 \\
-159.4 \\
+28.2 \\
-6.4 \\
+37.7 \\
-101.1 \\
-86.4 \\
-39.2 \\
+6.6 \\
-72.2 \\
-30.2 \\
+56.2 \\
-19.3 \\
+43.1 \\
-32.4 \\
+36.9 \\
-32.0 \\
-103.9\end{array}$ & $\begin{array}{l}-35.1 \\
+160.3 \\
-\quad 6.3 \\
-\quad 3.9 \\
-66.5 \\
+\quad 2.3 \\
-25.0 \\
+83.9 \\
+614.6 \\
-105.8 \\
-106.5 \\
-46.7 \\
-80.8 \\
-57.1 \\
+112.6 \\
-165.4 \\
+29.9 \\
-6.7 \\
+90.3 \\
-107.0 \\
-91.6 \\
-41.0 \\
+6.7 \\
-75.5 \\
+31.2 \\
+50.3 \\
-20.1 \\
+44.6 \\
-34.3 \\
+39.5 \\
-33.5 \\
-113.7\end{array}$ \\
\hline
\end{tabular}

a Se obtuvo directamente de la información censal. $M_{50-60}$.

b Se corrigió utilizando el índice de sobrevivencia intercensal de los migrantes de todo el país. $M_{50-60}=M_{60}-(.8862) M_{50}$.

c Se corrigió utilizando los índices de sobrevivencia intercensal de los migrantes de cada entidad. $M_{50-60}=M_{60}-{ }_{10} S_{m}^{E} M_{50}$ (los valores de ${ }_{10} S_{m}^{E}$ aparecen en el cuadro 4).

(I Se corrigió utilizando los índices de sobrevivencia intercensal de los migrantes intercensales de cada entidad. $M_{50-60}=M_{60}-{ }_{10} S_{m}^{E} M_{50} / 5 S_{m}^{E t}$ (los valores de $S_{5} S_{m}^{Z}$ aparecen en el cuadro 4 ). 
en el siguiente censo llevado a cabo $n$ años más tarde, tendrá las siguientes características:

a) los residentes que fueron enumerados en el primer censo a una edad $x$ tendrán $n$ años más de edad al segundo censo;

$b$ ) algunas personas que fueron enumeradas en el primer censo morirán en el transcurso de los $n$ años y no aparecerán en el segundo censo;

c) los niños nacidos durante el período intercensal serán enumerados en el segundo censo con edades menores de $n$ años.

Teniendo en cuenta estas características y con el conocimiento de índices o tasas de sobrevivencia que indiquen qué proporción de personas, en cada edad o grupo de edad, sobreviven los $n$ años, se puede estimar el número de individuos que al tiempo del segundo censo deberian estar presentes en la comunidad con edad $x+n$.

Si denotamos con ${ }^{0} P_{\boldsymbol{w}}^{E}$ a la población de una entidad cualquiera censada al inicio del intervalo con una edad $x ;{ }^{n} P_{x+n}^{E}$ a la población de la misma entidad censada $n$ años más tarde con edad $x+n$; ${ }_{n} S_{x}^{E}$ un índice decenal apropiado de sobrevivencia para la edad $x$, la migración neta para una cohorte será:

$$
M_{x+n}={ }^{n} P_{x+n}^{E}-{ }_{n} S_{x}^{E} \cdot{ }^{0} P_{x}^{E}
$$

El término ${ }_{n} \mathrm{~S}_{x}^{E} \cdot{ }^{0} P_{x}^{E}$ puede ser identificado como la población esperada con edad $x+n$ al final del período intercensal en ausencia de movimientos migratorios; es decir, la población inicial ${ }^{0} P_{x}^{E}$ solamente habrá experimentado pérdidas debido a las muertes ocurridas durante el intervalo. Esta población, cuando se compara con la de edad $x+n$, censada al fin del período, dará una estimación de la migración neta intercensal.

Este proceso sólo produce una estimación de la migración neta intercensal de la población de más de 10 años de edad y no es aplicable a las personas nacidas durante el intervalo. Para estimar la migración de menores de 10 años pueden seguirse procesos análogos, tomando los nacimientos ocurridos en la década y aplicándoles índices apropiados de sobrevivencia. ${ }^{10}$

Para que la expresión anterior se cumpla, es decir, que la migración neta intercensal sea igual al residuo de la población real y la población esperada, varios requisitos deben ser considerados:

1) que la población de la comunidad bajo estudio sea una población cerrada a la migración internacional; esto es, que la diferencia entre ${ }^{0} P_{x}^{E}$ y ${ }^{n} P_{x+n}^{E}$ sólo sea explicable en términos de defunciones y movimientos migratorios internos;

2) que los efectivos por edad de las poblaciones censadas al principio y al final del intervalo sean correctos, es decir, que no haya errores de cobertura o de declaración de edad; y

10 Más adelante se hará breve comentario sobre los procesos para estimar los migrantes en estas edades. 
3) que los índices de sobrevivencia sean correctos y apropiados para la población de la comunidad bajo estudio.

Por tratarse de una estimación en donde la migración neta es un residuo, el método de las tasas de sobrevivencia es altamente sensible cuando no se cumplen las condiciones anteriores. Todos los errores y discrepancias en la información básica afectarán directamente la determinación residual, que ha sido definida como el producto de los movimientos migratorios internos. En rigor, las estimaciones de la migración neta obtenidas por este método deberán ser interpretadas como una combinación de la migración neta y del balance neto de los errores en la información básica. Sólo cuando el balance neto de los errores sea cercano a cero puede ser interpretado el residuo como medida confiable de la migración neta.

Para examinar el efecto que produce la violación de estas condiciones, es necesario distinguir entre dos tipos de estimación de los índices de sobrevivencia: a) aquellos que se derivan de la función $L_{x}$ de una tabla de mortalidad; $b$ ) aquellos que se obtienen relacionando las cohortes en dos censos consecutivos. A los primeros se les conoce como índices de sobrevivencia de la tabla de vida y a los segundos se les identifica como índices de sobrevivencia censales.

El procedimiento básico comentado anteriormente es válido para el uso de ambos índices de sobrevivencia y sólo ciertos problemas relacionados con la información producen resultados diferentes. Si se cumplen los tres requisitos señalados, las estimaciones serán idénticas.

\section{Indices de sobrevivencia de tablas de vida}

Los índices de sobrevivencia de una tabla de vida son calculados a través de la función $L_{x}$ que representa los efectivos por edad de la población estacionaria de una tabla de vida. La relación $L_{x+n} / L_{x}$ da una estimación de la proporción de sobrevivientes de la población con edad $x$, al fin del período $n$. A esta relación se le ha denotado con el símbolo ${ }_{n} S_{x}$.

En la expresión $M_{x+n}={ }^{n} P_{x+n}^{E}-{ }_{n} S_{x}^{E} \cdot{ }^{0} P_{x}^{E}$, supongamos que ${ }^{0} P_{x}^{E}$ se refiere a la población censada de $x$ años de edad; ${ }^{n} P_{x+n}^{E}$ es la población de la misma entidad censada 10 años más tarde con edad $x+n$ años $y_{n} S_{x}^{E}$ el índice de sobrevivencia en donde se refleja la mortalidad ocurrida durante el intervalo intercensal de 10 años para la cohorte de $x$ años de edad. La estimación de la migración neta $M_{x+n}$ estará afectada por tres fuentes de error que corresponden a los requisitos señalados anteriormente:

Primero, los movimientos migratorios internacionales de los nativos pueden estar incluidos en la estimación de la migración neta. Esto es, que en el primer censo estén considerados en ${ }^{0} P_{x}^{E}$, mientras que en el segundo no lo estén en $P_{x+n}$; en este sentido resultará una 
subestimación si el monto de la migración neta es positivo y una sobrestimación si es negativo; en el caso contrario, si en ${ }^{0} \boldsymbol{P}_{x}^{E}$ no están considerados y al tiempo del segundo censo se incluyen en $P_{x+n}^{E}$, los errores serán opuestos a los anteriores.

Un segundo error parte de la inexactitud de la población enumerada al declarar su edad o al haber una sub o sobrenumeración en determinadas edades. Este tipo de errores tiene gran influencia en las estimaciones. Por ejemplo, se ha demostrado ampliamente que la población censada de 0 a 4 años de edad está afectada por fuerte subenumeración; si a esta población se le aplica un índice correcto de sobrevivencia de diez años y el resultado se compara con la población censada diez años después con edades entre 10 y 14 años, que por lo regular tiene elevado grado de exactitud, el volumen migratorio estimado, para esa cohorte, será una combinación del monto de la migración neta y del error contenido en la población de 0 a 4 años. Esta situación puede apreciarse tomando como ejemplo el caso concreto del estado de Agzascalientes: el censo de 1950 reportó $29900 \mathrm{ni}$ ños entre 0 y 4 años de edad, mientras que en 1960, el grupo censado de 10 a 14 años fue de 31000 personas. Si consideramos que el índice correcto de sobrevivencia de Aguascalientes, en el período intercensal, de las edades de 0 a 4 años es de .9275, la migración neta será de $31.0-.9275 \cdot 29.9=+3.3$.

Ahora bien, se ha estimado que el censo de Aguascalientes de 1950 sólo enumeró el $78 \%$ de la población del grupo de 0 a 4 años, es decir, que hubo una subenumeración del $22 \%$. El grupo de 10 a 14 años se consideró correctamente enumerado en 1960. El volumen de la migración neta con la población corregida del grupo 0-4 será $31.0-.9275 \cdot 38.3=-4.5$.

En este ejemplo se aprecia cómo la influencia de la subenumeración puede inclusive invertir el sentido del saldo migratorio neto.

La declaración errónea de la edad tiene efectos semejantes al caso anterior y en general puede decirse que el error contenido en el volumen dependerá del tamaño relativo de los errores en las poblaciones censadas al principio y al final del período. $S i{ }^{U} P_{x}^{E}$ y ${ }^{n} P_{x+n}^{L^{2}}$ son los verdaderos montos de las poblaciones; $0 \lambda^{E}$ y $n \lambda^{E}$ son los grados de enumeración de las poblaciones con edades $x$ y $x+n$ enumeradas respectivamente en el primero y el segundo censos, el volumen esti. mado de la migración neta $\bar{M}_{x+n}$ será:

$$
\bar{M}_{x+n}=n \lambda^{E} \cdot{ }^{n} P_{x+n}^{E}-{ }_{n} S_{x}^{E} \cdot{ }^{0} P_{x}^{E} \cdot 0 \lambda^{E}
$$

Si ${ }^{0} \lambda^{E}={ }^{E} \lambda^{E}$, es decir, que el error relativo en ambas poblaciones sea igual, el verdadero monto de la migración estará aumentado o disminuido por $0 \lambda^{E}$ (según ${ }^{D E} \lambda^{E}$ sea mayor o menor que la unidad); esto es, $\bar{M}_{x+n}=\emptyset \lambda^{E} \cdot M_{x+n}$, donde $M_{x+n}$ es el monto correcto de la migración. Por último, los índices de sobrevivencia que se emplean pueden no reflejar con exactitud la experiencia de la mortalidad intercensal de la población. Esto puede deberse a deficiencia en los registros de 
las defunciones sobre los cuales está basada la tabla de mortalidad. Asimismo, los índices reflejan las condiciones de la mortalidad al principio y al final del período intercensal, más que las condiciones durante el intervalo. Esta dificultad puede subsanarse en parte promediando las tasas de sobrevivencia del principio y del final del período. Se obtendrán así las condiciones medias del período, introduciendo ciertos supuestos aproximados. Por otro lado, hay que considerar que, por lo general, en la construcción de las tablas de mortalidad, los indices de sobrevivencia son el producto de correcciones que se han hecho a la información original para modificar los efectos de la subenumeración, la declaración errónea de las edades y las fluctuaciones erráticas de las tasas de mortalidad. Debido a esto, cuando los índices de sobrevivencia son aplicados a la información imperfecta de los censos pueden producirse desviaciones altamente significativas en la estimación de la migración neta.

Una limitación importante de este método es que suelen no encontrarse disponibles tablas de mortalidad de las diversas regiones de un país (caso muy común en América Latina). De aquí que un procedimiento frecuente haya sido emplear índices de sobrevivencia del país en su conjunto y aplicarlos a la población de los estados, bajo la hipótesis de que la mortalidad de las entidades no difiere mucho de la nacional. Otro recurso es adaptar la tabla del país a las condiciones locales, con base en información sobre el nivel relativo de la mortalidad de las distintas regiones. En este sentido podrían utilizarse tablas modelo de mortalidad. ${ }^{11}$

\section{Indices de sobrevivencia censales}

Un segundo método para estimar los índices de sobrevivencia del período decenal consiste en relacionar el número de personas de una misma generación, o de un grupo de generaciones, en dos censos consecutivos del total del país. Es decir, el índice de sobrevivencia para una cohorte dada es:

$$
{ }_{n} S_{x}^{T}=\frac{{ }^{n} P_{x+n}^{T}}{{ }^{0} P_{x}^{T}}
$$

en donde ${ }^{0} P_{x}^{T}$ es el número de personas nativas de edad $x$ enumeradas en el primer censo y ${ }^{n} P_{x+n}^{T}$ es el número de personas nativas de edad $x+n$, enumeradas en el segundo censo $n$ años más tarde. En ambos casos, las poblaciones son los totales del país.

La expresión para estimar la migración neta de las entidades usando este tipo de índice de sobrevivencia, que se ha representado con el símbolo ${ }_{n} S_{x}^{T}$, es :

$$
M_{x+n}={ }^{n} P_{x+n}^{E}-{ }_{n} S_{x}^{T} \cdot{ }^{0} P_{x}^{E}
$$

11 Naciones Unidas, Métodos para preparar proyecciones de población por sexo y edad, ST/SOA/Serie A, Núm. 25, Nueva York, 1956; A. J. Coale y Paul Demeny, Regional Model Life Tables and Stable Populations, Princeton, Princeton University Press, 1966. 
donde ${ }^{0} P_{x}^{E}$ y ${ }^{n} P_{x+n}^{E}$ son las poblaciones de la entidad, a edades $x$ y $x+n$, enumeradas en dos censos consecutivos.

Considerando las fuentes de errores que se derivan del no cumplimiento de los tres requisitos establecidos en un principio, las estimaciones por este método estarán afectadas como se indica a continuación.

La importancia de que la población no esté sujeta a movimientos internacionales se debe al hecho de que los índices de sobrevivencia están estimados por el cociente ${ }^{n} P_{x+n}^{T} /{ }^{0} P_{x}^{T}$. Esta relación será un indice de sobrevivencia sólo si ${ }^{n} P_{x+n}^{2}$ incluye únicamente a los sobrevivientes de la población ${ }^{0} P_{x}^{T}$. Si esta condición es violada por la migración internacional, el monto de la verdadera migración de un estado estará afectado por un error que puede establecerse de la siguiente manera:

Supongamos que el número de personas a una edad $x+n$, enumeradas en el total del país en el segunao censo, es superior a los sobrevivientes de ${ }^{0} r_{x}^{T}$ en una cantidad que se designa como $\Lambda^{1}$ y que corresponde a la iminigración internacional al pais en su conjunto; esto es, si la población nubiera estado cerrada, el número de personas con edad $x+n$, enumeradas en el segundo censo, habría sido ${ }^{n} r_{x+n}^{T}$; pero en realidad la población enumerada fue de ${ }^{n} f_{x+n}^{T}+I^{T}$. El índice de sobrevivencia correcto es ${ }^{n} P_{x+n}^{T} /{ }^{0} P_{x}^{T}$, mientras que el estimado es $\left({ }^{n} P_{w+n}^{T}+I^{T}\right) / H_{x}^{T}$. De acuerdo con esto, se tendrá que el monto verdadero de la migración neta del estado que no está afectado por este error es:

$$
M_{x+n}={ }^{n} P_{x+n}^{E}-\frac{{ }^{n} P_{x+n}^{T}}{{ }^{0} P_{x}^{T}} \cdot{ }^{0} P_{x}^{E}
$$

y el volumen de la migración interna incluyendo la migración internacional es:

en donde

$$
\bar{M}_{x+n}={ }^{n} P_{x+n}^{E}-\frac{{ }^{n} P_{x+n}^{T}+I^{T}}{{ }^{0} P_{x}^{T}} \cdot{ }^{0} P_{x}^{E}
$$

o de otra forma:

$$
\bar{M}_{x+n}={ }^{n} P_{x+n}^{E}-\frac{{ }^{n} P_{x+n}^{T}}{{ }^{0} P_{x}^{T}} \cdot{ }^{T} P_{x}^{E}-I^{T} \cdot \frac{{ }^{0} P_{x}^{E}}{{ }^{0} P_{x}^{T}}
$$

$$
\bar{M}_{x+n}=M_{x+n}-I^{T} \cdot \frac{{ }^{0} P_{a}^{E}}{{ }^{x} P_{x}^{T}}
$$


De aquí que si $I^{T}$ es positivo, la migración estimada con relación a un estado en particular estará subestimada (con significado algebraico) en un monto que dependerá de la proporción de la población del estado con relación a la población total del país al principio del intervalo.

En caso de que a la poblacion del estado ${ }^{n} P_{w+n}^{L^{\prime}}$ le corresponda una parte de la migración internacional total $I^{T}$, es decir, que la población censada del estado sea ${ }^{n} P_{x+n}^{E}+I^{E}$, siendo $I^{E}$ una parte de la migración internacional total, el monto de la migración interna estará afectado en la siguiente forma:

$$
\begin{aligned}
& \bar{M}_{x+n}={ }^{n} P_{x+n}^{E}+I^{E}-\frac{{ }^{n} P_{x+n}^{T}+I^{T}}{{ }^{0} P_{x}^{T}} \cdot{ }^{0} P_{x}^{E^{E}} \\
& =\left({ }^{n} P_{x+n}^{E}-\frac{{ }^{n} P_{x+n}^{T}}{{ }^{0} P_{x}^{T}} \cdot{ }^{0} P_{x}^{E}\right)-\left(-I^{E}+I^{T} \cdot \frac{{ }^{0} P_{w}^{E}}{{ }^{0} P_{x}^{T}}\right) \\
& =M_{x+n}-\left(-I^{E}+I^{T} \cdot \frac{{ }^{0} P_{x}^{E}}{{ }^{0} P_{x}^{T^{\prime}}}\right)
\end{aligned}
$$

Por lo tanto, el verdadero monto de la migración $M_{x+n}$ estará desviado por una cantidad igual al volumen de la migración internacional del estado, corregido por una parte de la migración internacional total del país. Si $I^{E}$ es igual a cero, se tendrá el caso anterior y la migración estará subestimada; conforme $I^{E}$ se vaya incrementando, la subestimación disminuirá hasta un punto en que no haya error y a partir de ahí con el aumento de $I^{E}$ habrá una sobrestimación de la migración (algebraicamente).

En la misma forma puede establecerse el caso en que haya migración internacional del país con saldo negativo, ya sea que afecte o no a la entidad.

La siguiente fuente de error que corresponde a la segunda condición expuesta inicialmente se refiere a la enumeración incorrecta de las cohortes de las poblaciones censadas.

Si denotamos con $0 \lambda^{E}$ y $n \lambda^{E}$ el grado de enumeración de la población de un estado en el primer y segundo censos, respectivamente, y a ${ }^{0} P_{a}^{E}$ y ${ }^{n} P_{a+n}^{L}$ los montos correctos de la población, se tiene entonces que $0 \lambda^{E} \cdot{ }^{0} P_{x}^{E}$ y ${ }^{n} \lambda^{E} .{ }^{n} P_{w+n}^{b^{\prime}}$ serán las poblaciones enumeradas. De la misma forma $0 \lambda^{T}$ y $n \lambda^{T^{\prime}}$ representan el grado de enumeración de las poblaciones en el total del país. 
Como se ha establecido anteriormente, el monto verdadero de la migración neta de un estado cualquiera es:

$$
M_{x+n}={ }^{n} P_{x+n}^{E}-\frac{{ }^{n} P_{x+n}^{T}}{{ }^{0} P_{x}^{T}} \cdot{ }^{0} P_{s}^{E}
$$

y el monto estimado de la migración estará dado por:

$$
\begin{aligned}
\bar{M}_{x+n} & ={ }^{n E} \cdot{ }^{n} P_{x+n}^{E}-\frac{{ }_{n \lambda^{T} \cdot{ }^{n} P_{x+n}^{T}}}{{ }^{0} \lambda^{T} \cdot{ }^{0} P_{x}^{T}} \cdot 0 \lambda^{E} \cdot{ }^{0} P_{x}^{E} \\
& ={ }^{E} \lambda^{E}\left({ }^{n} P_{x+n}^{E}-\frac{{ }^{n} \lambda^{T}}{{ }^{T} \lambda^{T}} \cdot \frac{{ }^{0} \lambda^{E}}{{ }^{E} \lambda^{E}} \cdot \frac{{ }^{0} P_{x+n}^{T}}{{ }^{0} P_{x}^{T}} \cdot{ }^{0} P_{x}^{E}\right)
\end{aligned}
$$

El significado de la condición (2) puede ser observado claramente en la expresión anterior. Aun bajo el supuesto de que los censos de principio y final del intervalo tengan el mismo grado de enumeración en sus respectivas edades, el monto de la migración estimada $\bar{M}_{x+n}$ diferirá del verdadero $M_{x+n}$ en una cäntidad que dependerá del grado de enumeración de la población del estado censada al final del período $\left(n \lambda^{m}\right)$.

Utilizando nuevamente el caso del estado de Aguascalientes, se da a continuación un ejemplo de la influencia de los errores de enumeración. Se ha dicho que el grupo de 0 a 4 años censado en 1950 tenía un grado de enumeración de ${ }^{0} \lambda^{E}=.78$; el de la población total de México en esa misma edad y año fue de ${ }^{0} \lambda^{T} \doteq .86$. Se ha considerado que las poblaciones de 10 a 14 años de edad censadas en 1960 fueron enumeradas correctamente tanto en el estado como en el país, es decir, que $n \lambda^{T}$ y ${ }^{n} \lambda^{W}$ son iguales a la unidad. Las poblaciones correctas en 1950 y 1960 serán:

$$
\begin{array}{ll}
{ }^{1950} P_{0-4}^{T}=4611.3 \text { miles } & { }^{1950} P_{0-4}^{E}=38.3 \text { miles } \\
{ }^{1960} F_{10-14}^{T}=4358.7 \text { miles } & { }^{1960} P_{10-14}^{E}=31.0 \text { miles }
\end{array}
$$

De acuerdo con la expresión para estimar la migración se tendrá:

$$
\begin{aligned}
\bar{M}_{10-14} & =1.00 \quad\left(31.0-\frac{1.00}{0.86} \cdot \frac{0.78}{1.00} \cdot \frac{4358.3}{4611.3} \cdot 38.3\right) \\
& =31.0-0.91 \cdot .9451 \cdot 38.3=-1.9
\end{aligned}
$$

Ahora bien, si se supone teóricamente que las poblaciones enumeradas son las mismas que las correctas y el índice de sobrevivencia apropiado es de .9451, el monto verdadero de la migración interna sería:

$$
M_{10-14}=31.0-.9451 \cdot 38.3=-5.2
$$


La diferencia que se observa en los resultados se debe a la influencia de los grados de enumeración en los dos censos. En este caso sólo se ha considerado la subenumeración en un grupo de edades (0 a 4 años). Si se considera que existen errores en diversos sentidos en todos los grupos de edades que intervienen en el cómputo, se complica mucho más aún el establecimiento del sentido y magnitud del error total y no hay medio adecuado de resumir el efecto combinado de todos ellos. En la práctica, se cuenta con muy poca evidencia directa sobre los errores censales y sus variaciones regionales; las estimaciones que se hagan para determinar dichos errores y tratar de corregirlos pueden también estar desviadas, corriéndose el peligro de confundir verdaderos movimientos migratorios con errores de enumeración. Las encuestas post-censales llevadas a cabo en algunos países indican, en forma general, que las variaciones regionales en los errores censales son en algunos casos muy amplias. Esto es de esperar que suceda con más intensidad en los países en que exista gran hetereogeneidad en las condiciones socioeconómicas regionales. México puede encontrarse en este caso, ya que se observan fuertes contrastes a nivel estatal, por ejemplo, en alfabetismo, urbanización, facilidades de comunicación, etc. En otro sentido, se pueden esperar diferentes calidades en la organización administrativa censal, que traigan como consecuencia variaciones en la exactitud de las enumeraciones en las diversas entidades o regiones.

De estas breves consideraciones puede concluirse que la hipótesis que comúnmente se establece para la aplicación de los índices de sobrevivencia censales y que consiste en suponer que los errores de enumeración a nivel nacional son de la misma intensidad y dirección que los que se dan a nivel regional $\left(0 \lambda^{T}=0 \lambda^{E}\right.$ y $\left.n \lambda^{T}={ }^{T} \lambda^{E}\right)$, es difícil que se dé en la práctica y sólo es una forma simplista de hacer una evaluación menos complicada del efecto que produce este tipo de errores.

A pesar de los problemas que se presentan en el uso de los índices de sobrevivencia censales para la estimación de la migración neta interna, tienen la ventaja sobre los índices de una tabla de vida de que cancelan en parte los errores contenidos en los datos censales. Esto es, los índices censales no sólo miden la sobrevivencia de una cohorte, sino que actúan como factores de corrección para los errores de enumeración que afectan a las distribuciones por edad. Esto no quiere decir que los elimina del todo, pero al menos los disminuye en parte.

En el cuadro 7 se comparan los índices de sobrevivencia censales con los de la tabla de vida de México que representan las condiciones a mitad del período intercensal con una vida media de 54.3 años.

Como puede observarse, hay amplias diferencias entre los índices de sobrevivencia censales y los de las tablas de vida, lo que indicaría considerables errores de enumeración en uno o en ambos censos. Respecto al grupo de edad más joven, 0 a 4 años, el error puede ser explicado por la conocida subenumeración de los niños menores de 5 años. Para los otros grupos de edades la situación no es muy clara y deben buscarse diferentes explicaciones.

Las mayores diferencias se dan en los grupos de edades extremas, 0 a 4 y 70 y más; el primero se explica por la razón dada antes y 


\section{Cuadro 7}

MÉXICo: Índices de SOBREVIVENCIa CENSALES E ÍNDICES DE SOBREVIVENCIA DE LA TABLA DE VIDA POR GRUPOS DE EDAD, 1950-1960

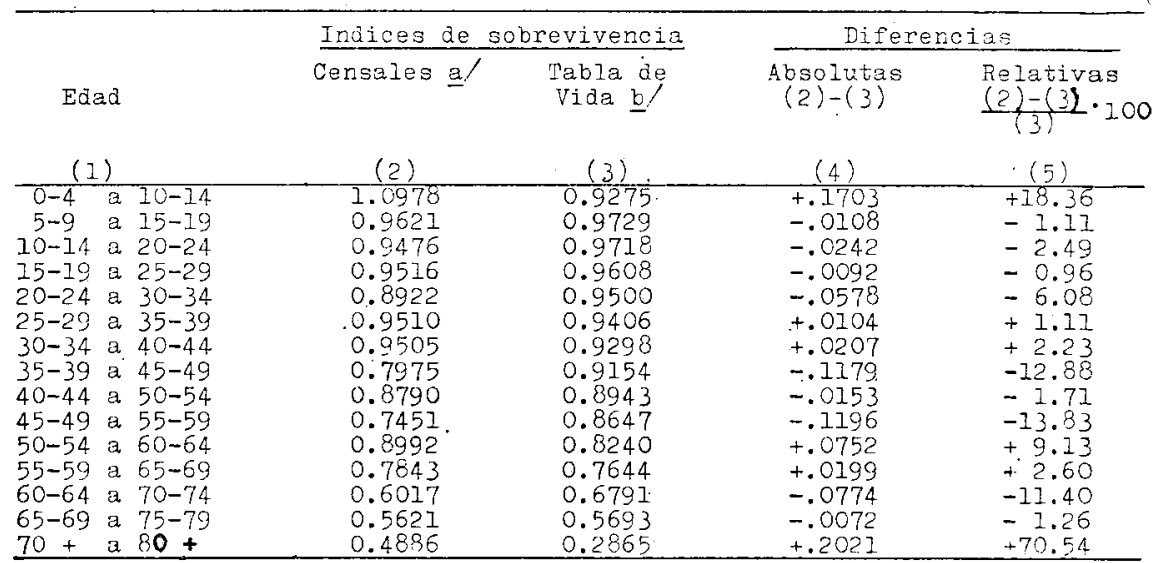

a Estos valores fueron obtenidos con la información publicada en los Resúmenes Generales de los VII y VIII Censos generales de población.

b Estos valores se estiman promediando los índices de sobrevivencia de la tabla de vida de México de 1950 y 1960.

el de 70 y más, que difiere en un $70 \%$ del índice de la tabla de vida, debe ser tomado con mucha reserva ya que no se tiene ninguna seguridad de que este último sea correcto. El elevado valor del índice censal puede ser atribuible a la tendencia general de las personas de avanzada edad a declarar un número mayor de años de los que en realidad tienen. Por otro lado, no se tiene confianza en el índice de sobrevivencia de la tabla de vida debido a la calidad diferente de los registros de defunciones. No obstante, parece ser que el verdadero índice estaría más cercano al de la tabla de vida.

En los grupos de 20-24, 35-39, 45-49, 50-54 y 60-64 años, aparecen también fuertes discrepancias en los valores de los índices, aunque en menor grado que en los grupos comentados anteriormente. Exceptuado el grupo 50-54, los índices censales de las otras edades presentan valores que están por abajo de los de la tabla de vida. Esta situación es el reflejo de la combinación de los errores en la declaración de edad en ambos censos. Pero no es posible determinar el rango de error, debido a información insuficiente y a la falta de elementos independientes comprobatorios de la exactitud de los censos. En términos generales, sólo puede decirse que los errores mayores de enumeración se encuentran entre la población infantil y en la población de más de 40 años.

Por último, queda el problema de que los índices de sobrevivencia censales sean correctos y apropiados para la población del área bajo estudio. 
En el punto anterior se comentó que los índices de sobrevivencia censales reflejan tanto la mortalidad experimentada por la población del país durante el decenio como los errores de enumeración de los censos. En principio se puede aceptar que dichos índices son correctos para el cumplimiento de su doble función. Anora bien, queda por ver si estos índices son apropiados para utilizarlos en las poblaciones de las entidades del país.

" Como se ha señalado, el método de indices de sobrevivencia supone la aplicación de los índices censales, que representan la sobrevivencia media del país a la población de cada entidad para obtener la población esperada al final del período. El hecho de utilizar los índices a nivel nacional supone dos condiciones: a) que el grado de enumeración de los censos al principio y al final sean iguales tanto para la población total del país como para la población de las entidades; y b) que haya ausencia de diferenciales geográficos en la mortalidad de las entidades; es decir, que los índices de sobrevivencia de cada estado sean iguales a los del total del país.

La primera condición ha sido ya comentada. La segunda, obviamente, no se cumple, y el error que introduce en las estimaciones de la migración dependerá del tamaño del país, del número de estados y de las condiciones de la mortalidad general. El error que se tiene al aceptar esta condición puede ser representado en la siguiente forma:

La estimación de la migración neta en un estado es igual a:

$$
\bar{M}_{x+n}={ }^{n} P_{x+n}^{E}-{ }_{n} S_{x}^{T} \cdot{ }^{n} P_{x}^{E}
$$

en donde ${ }_{n} S_{x}^{T}$ es el índice de sobrevivencia del total del país; las otras funciones son la población censada al final y al principio del período de un estado.

La migración verdadera de ese mismo estado es:

$$
M_{x+n}={ }^{n} P_{x+n}^{E}-\left({ }_{n} S_{x}^{T}-\Delta_{n} S_{x}\right){ }^{0} P_{x}^{E x}
$$

en donde $\Delta_{n} S_{x}$ es la diferencia entre el índice de sobrevivencia nacional y el del estado $\left(\Delta_{n} S_{x}={ }_{n} S_{x}^{T}-{ }_{n} S_{x}^{E}\right)$.

Se tendrá entonces

$$
M_{x+n}={ }^{n} P_{x+n}^{E}-{ }_{n} S_{x}^{T} \cdot{ }_{n}^{0} P_{x}^{E}+\Delta_{n} S_{x}{ }^{0} P_{x}^{E}
$$

o bien

$$
M_{x+n}=\vec{M}_{x+n}+\Delta S_{x}{ }^{0} P_{x}^{E}
$$

Es decir, la migración verdadera $\left(M_{x+n}\right)$ es igual a la estimada $\left(\bar{M}_{n+n}\right)$ más un factor que equivale al producto de la diferencia de mortalidad por la población inicial.

Este factor, que en realidad es el error, puede tomar valores absolutos muy grandes, dependiendo su monto de la diferencia entre los índices de sobrevivencia. En México se observa que durante el 
período 1950-1960, el índice de sobrevivencia nacional fue de $.9128^{12}$ para el conjunto de las edades. Los valores máximo y mínimo de los índices correspondientes de los estados fueron $.9557^{12}$ y $.8863, t^{12}$ respectivamente. Estos índices pertenecen, en ese orden, a las entidades de Quintana Roo y Puebla. De esta forma se tiene que las diferencias extremas tomarán los valores de (-) .0429 y .0265 , es decir, que $\Delta S_{x}$ está comprendido en un rango que abarca esas dos cantidades y el error que se incorpora al aceptar la condición de igualdad regional en la sobrevivencia tiene magnitudes apreciables, e inclusive puede llegarse al caso de que el sentido de la migración neta se invierta.

En resumen, las pocas evidencias directas que se tienen del problema indican que el error en las estimaciones de la migración neta debido a las diferencias regionales de la mortalidad debe ser tomado en cuenta para la interpretación de los resultados.

Estimaciones de la migración neta para personas menores de 10 años de edad

Como se apuntó al principio de este capítulo, el método de índices de sobrevivencia no produce una estimación de la migración neta para las personas menores de 10 años. Para esto es necesario introducir otro proceso que complemente al anterior. En este sentido, hay varios procesos que pueden ser adoptados según la información disponible y su calidad.

Un sistema que tiene características semejantes al método de índices de sobrevivencia es el siguiente: la población que nace durante el intervalo y que sobrevive al finalizar éste con edades comprendidas entre 0 y 9 años puede estimarse a partir de los nacimientos anuales registrados, aplicándoles las probabilidades de sobrevivencia respectiva que abarquen el número de años entre la fecha de nacimiento y la del segundo censo. Este procedimiento produce una estimación del número de niños sobrevivientes al segundo censo que nacieron durante el decenio. La diferencia entre el número esperado de tales niños y el número de los censados al final del intervalo entre edades de 0 y 9 años, dará una estimación de la migración neta para la población menor de 10 años durante el intervalo.

Como se dispone usualmente de cifras de población censada por grupos quinquenales de edad, si se toman los nacimientos de los primeros cinco años del decenio y se les aplica su respectivo índice de sobrevivencia, se obtendrá al final del intervalo la población esperada entre 5 y 9 años de edad. De la misma manera, aplicando el índice de sobrevivencia respectivo al número de nacimientos en los segundos cinco años se tendrán los sobrevivientes al final con edades entre 0 y 4 años. La expresión de este proceso es:

$$
\begin{aligned}
& M_{0-4}={ }^{n} P_{0-4}^{W}-{ }_{5} S_{b}^{E} \cdot B_{n / 2-n}^{D} \\
& M_{5-9}={ }^{n} P_{5-9}^{E}-{ }_{10} S_{b}^{E} \cdot B_{0-n / 2}^{E}
\end{aligned}
$$

12 Estos valores se tomaron del cuadro 4. 
en donde ${ }^{n} P_{0-4}^{E}$ y ${ }^{n} P_{5-9}^{E}$ son las poblaciones entre 0 a 4 años y 5 a 9 años de edad de un estado, enumeradas en el segundo censo; $B_{0-n / 2}^{E}$ y $B_{n / 2-n}^{E}$ son los nacidos en la misma entidad durante el primero y segundo quinquenios del intervalo respectivamente; ${ }_{10} S_{b}^{E}$ y ${ }_{5} S_{b}^{E}$ son los índices de sobrevivencia que indican la proporción de sobrevivientes al final del período de los nacidos durante el primero y segundos quinquenios del intervalo.

El éxito del sistema descansa en las mismas consideraciones que el método de sobrevivencia, es decir, el grado de exactitud de los nacimientos registrados y de la población enumerada, y de que los índices sean correctos y apropiados para la población.

En la práctica, es difícil lograr estas condiciones, y por lo que toca a México ya se ha hecho notar la fuerte subenumeración que existe en las edades de 0 a 4 años, así como también el subregistro de los nacimientos. Otra dificultad es la de no contar con los índices de sobrevivencia de las tablas de vida a nivel regional; pero aun si se contara con ellos, el aplicarlos a poblaciones defectuosas produciría resultados de poca confianza. Podría pensarse en tratar de corregir la subenumeración de los grupos de edad, pero se correría nuevamente el riesgo de ocultar una migración verdadera.

Otro sistema ${ }^{13}$ que puede ser utilizado es a través de la relación de niños de 0 a 9 años de edad y las mujeres de 15 a 49 años. El procedimiento es el siguiente:

a) se computa la relación entre el número de niños de 0 a 4 años y el de mujeres de 15 a 44, así como también la que existe entre niños de 5 a 9 y mujeres de 20 a 49 años, enumerados en cada estado en el último censo;

b) a la población esperada de mujeres al final del período, entre las edades consideradas, se aplican las relaciones niños-mujeres obtenidas en el punto anterior, suponiendo que dicha relación es por lo menos igual a la que se daría entre la población esperada. Se obtiene así una estimación del volumen de niños nacidos en la década provenientes de padres no migrantes y que sobrevivieron al final del período;

c) estos números, al restarlos del número de niños enumerados en el último censo entre las edades de 0 a 4 y 5 a 9 años de edad, dan una estimación de los niños nacidos de padres migrantes y que sobrevivieron al final del intervalo intercensal. Algunos de estos niños nacieron antes de que sus padres migraran y otros después; y

d) suponiendo que la migración estuvo distribuida uniformemente durante la década, un medio de estos volúmenes puede ser considerado como una estimación del número de niños que podrían clasificarse como migrantes. 
Un método alternativo ${ }^{14}$ es aplicar directamente la relación niñosmujeres a la población de mujeres migrantes en edades de 15 a 44 y 20 a 49 años en cada entidad, bajo los supuestos de una migración uniforme durante el decenio y una tasa de fecundidad constante de año en año durante el mismo; un cuarto de los niños de 0 a 4 años y tres cuartos de aquellos en edades entre 5 a 9 años representan la migración neta de la población con edades de 0 a 9 años.

Estos procesos, utilizados frecuentemente, producen estimaciones muy crudas de la migración neta respecto a esas edades y se consideran apenas como sustitutos de métodos directos.

\section{Conclusiones sobre el método de indices de sobrevivencia}

De los comentarios que han sido hechos anteriormente pueden establecerse dos conclusiones generales:

1) Debido al hecho de que las estimaciones de la migración neta a través de este método son de carácter residual, es decir, que después de sustraídos otros componentes de cambio el remanente se toma como monto de la migración, todos los errores y discrepancias en la información básica entran directamente en la determinación del residuo y son considerados como parte de la inmigración o emigración. De aquí que la deficiencia fundamental de esta técnica sea su carácter residual, altamente sensitivo a las tres fuentes de errores descritos.

2) Existe un número de razones para preferir los índices de sobrevivencia censales a los basados en tablas de vida. Los argumentos son los siguientes:

a) los indices de sobrevivencia de las tablas de vida basadas en la información de los registros de muerte y la población censada, generalmente se corrigen y suavizan con objeto de modificar el efecto de la subenumeración, la declaración errónea de la edad y las fluctuaciones erráticas de las tasas de mortalidad, y cuando son aplicados a la información censal imperfecta los resultados quedan altamente influidos de esos factores. Los índices de sobrevivencia censales tienen la ventaja de que son una combinación de índices de sobrevivencia y un factor de corrección de los errores censales;

b) las tablas de vida no cubren la experiencia de la mortalidad durante el período intercensal, pues están basadas en la mortalidad al principio y al final del período. Los índices censales cubren todo el decenio; y

c) muchos países no cuentan con tablas de mortalidad a nivel nacional y menos aún por divisiones administrativas mayores o por regiones, y es necesario acudir a índices de cualquier tabla de vida que supuestamente sea válida para representar la mortalidad por edad en el país o región.

Teniendo en cuenta lo anterior, puede decirse que en países con características semejantes a las de México la aplicación de los índices

14 Lee et al., op. cit., p. 65. 
de sobrevivencia censales ofrece mejores resultados, y es probable que en muchos casos no haya otra alternativa que adoptar.

Se han hecho diversos intentos para mejorar las estimaciones basadas en índices de sobrevivencia considerando el problema de las variaciones regionales en la mortalidad. En cuanto a la corrección de las otras fuentes de errores, poco se ha hecho debido a la falta de elementos independientes para medir los errores censales y a la carencia de información sobre la migración internacional.

Algunos autores han resuelto el problema de las diferencias regionales de la mortalidad aplicando simplemente la sobrevivencia de las tablas de vida de cada estado, cuando éstas existen. Un método combinado, sugerido por Hamilton y Henderson, ${ }^{15}$ consiste en lo siguiente: a) suponen la existencia de tablas de vida tanto nacional como para cada estado; $b$ ) para cada estado, se calculan las diferencias en cada grupo de edad entre los índices de sobrevivencia de su tabla de vida y los índices de sobrevivencia de la tabla de vida nacional; c) las diferencias de cada estado se agregan a los índices de sobrevivencia censales del total del país, para obtener una serie de índices censales corregidos por la mortalidad local y aplicables a cada estado. Este sistema de mejoramiento de los índices de sobrevivencia concede implícitamente una ventaja a los índices censales sobre los de la tabla de vida.

En el estudio de Lee ${ }^{16}$ se hace un análisis de las variaciones regionales de la mortalidad en los Estados Unidos observando las diferencias por sexo y edad entre los índices de sobrevivencia de la tabla de vida nacional y los índices de las tablas de los estados en los años 1929-31 y 1939-41. Aunque se manifiestan diferencias apreciables, el autor consideró más apropiado no efectuar ningún tipo de corrección por mortalidad diferencial, y utilizó los índices de sobrevivencia censales de todo el país en las estimaciones de la migración interna de 1870 a 1950 .

En su tesis doctoral sobre la migración en la India, 1901-1931, K. C. Zachariah ${ }^{17}$ ajusta sus estimaciones por las diferencias en mortalidad en las provincias y por subenumeración y declaración errónea en la distribución por edad. El proceso que siguió el autor se resume así : a) la distribución de la población por edad de cada estado en los diferentes censos se suavizó mediante un proceso mecánico con objeto de corregir la influencia de la declaración errónea de la edad. La población por edad de cada entidad, efectuado el suavizamiento, fue sumada para obtener la distribución por edad del país y se calcularon los índices de sobrevivencia censales mediante la expresión usual. $b$ ) A efecto de corregir la subenumeración, concentrada principalmente en los grupos de edades de 5 a 9 hasta 25-29 años, se supuso un comportamiento lineal de la estructura porcentual tomando como base los puntos extremos. Los porcentajes que corresponden a los grupos inter-

15 C. H. Hamilton y F. M. Henderson, "Use of Survival Rate Method in Measuring Net Migration", Journal of the American Statistical Association, junio de 1944.

16 Lee et al., op. cit.

17 K. C. Zachariah, Historical Study of Internal Migration in the India Subcontinent, 1901-1931; A Dissertation in Sociology, Universidad de Pennsylvania, 1962. 
medios fueron estimados y sus valores se interpretaron como los correctos. El grado de enumeración en los tres grupos fue estimado relacionando los porcentajes observados y los corregidos. c) Se obtuvo una primera estimación de la migración neta usando la expresión $\bar{M}=P^{2}{ }_{i}-S P^{1}{ }_{i}$ en donde $S$ es el índice de sobrevivencia censal del país y $P_{i}^{1}$ y $P^{2}{ }_{i}$ las poblaciones de los estados al principio y al final del intervalo.

Los resultados de esta primera aproximación fueron corregidos: 1) por las diferencias estatales en mortalidad, mediante la expresión $M=\bar{M}+C_{i}\left(S P^{1}{ }_{i}\right)$. Es decir, la estimación corregida es igual a la no corregida más $C_{i}$ veces la población esperada sin corregir; $C_{i}$ se define mediante la relación:

$$
C_{i}=1-\frac{\text { Indice de sobrevivencia del estado }}{\text { Indice de sobrevivencia nacional }}
$$

Ambos índices son los de las tablas de vida respectivas. 2) Por subenumeración en los grupos de 5-9 a 25-29, dividiendo la estimación no corregida de la migración por el grado de enumeración correspondiente (ver inciso $b$ anterior).

Resultados de la estimación de la migración interna en México, 19501960, a través del método de indices de sobrevivencia

Se han calculado dos juegos de estimaciones de la migración interna, correspondientes uno al uso de los índices de sobrevivencia de la tabla de vida y otro a la aplicación de índices censales. Los procedimientos seguidos se resumen a continuación:

Estimaciones basadas en los indices de sobrevivencia de las tablas de vida. Respecto a los años censales 1950 y 1960, México cuenta con tablas de vida tanto nacionales como para cada una de las entidades federativas. ${ }^{18}$ Estas tablas se basan en la mortalidad registrada en los años 1949-51 y 1959-61. Las esperanzas de vida que se derivan de las tablas a nivel de entidad debieron ser consideradas en general con algunas reservas, ya que en ocasiones el nivel alcanzado no correspondió al grado de desarrollo económicosocial medido a través de indicadores simples como alfabetismo, grado de urbanización, población económicamente activa dedicada a labores primarias, etc. En vista de esto, se formaron cuatro grupos de entidades cuyas condiciones socioeconómicas fuesen más o menos similares. Para estos cuatro grupos se construyeron sus respectivas tablas de vida. ${ }^{19}$ Los índices de sobrevivencia representativos del intervalo intercensal de cada uno de los grupos fueron estimados promediando los índices del principio y final del decenio.

18 Raúl Benítez Zenteno y Gustavo Cabrera, op. cit.

19 En realidad fueron sólo tres tablas, ya que las condiciones de uno de los cuatro grupos eran muy similares a las condiciones medias del país, por lo que se adoptó para ése grupo la tabla de vida nacional. 
Como se anotó anteriormente, los índices de sobrevivencia de las tablas de vida son producto de una serie de ajustes en donde los errores han sido cuidadosamente removidos mediante refinamientos actuariales; en consecuencia cuando estos índices son aplicados a información censal imperfecta, parte del volumen de la migración neta es apenas el resultado de los errores en la declaración de edad o de los diferentes grados de enumeración de las cohortes en dos censos consecutivos. Debido a esto, algunos autores ${ }^{20}$ recomiendan que cuando se emplee este tipo de índices es necesario, cuando menos, corregir la información censal por subenumeración de la población menor de cinco años de edad.

En vista de que no se tienen elementos firmes para efectuar correcciones a las estructuras por edad de los estados y suprimir o disminuir en parte los efectos de la subenumeración o la declaración errónea en todas las edades, se corrigió solamente el efecto de la subenumeración en el grupo de edades de 0 a 4 años en cada una de las entidades. ${ }^{21}$ Por supuesto que esta corrección es muy parcial y se efectuó pensando que al menos el error de la subenumeración, concentrado casi en su mayor parte en ese grupo, podría disminuirse.

Efectuada la corrección a la población de los estados censada en 1950 , se le aplicaron sus respectivos índices de sobrevivencia y se obtuvo la población esperada en 1960. Ésta fue comparada con la población censada en 1960 en cada grupo de edad y la diferencia se tomó como el número de migrantes del decenio 1950-1960 que sobrevivieron a 1960 . La suma de los migrantes de cada grupo de edad es el monto estimado de la migración neta que corresponde a los sobrevivientes de más de 10 años de edad.

El número de migrantes menores de 10 años de edad en cada entidad se estimó tomando los nacimientos del decenio y aplicándoles sus respectivos índices de sobrevivencia para obtener la población esperada entre 0 y 9 años de edad al final del mismo. La diferencia entre el número de niños esperados y el de enumerados en el último censo, corregido también por subenumeración, representó la migración neta de la población menor de diez años.

En el cuadro 8 se presentan los resultados de estos procesos.

Estimaciones basadas en los indices de sobrevivencia censales. Los índices de sobrevivencia utilizados fueron obtenidos con la relación ${ }_{10} S_{x}^{T}={ }^{60} P_{x+10}^{T} /{ }^{50} P_{x}^{T}$, tomando la población de cada cohorte de todo el país censada al principio y al final del período. La migración neta fue estimada mediante la expresión usual: $\bar{M}_{x+n}={ }^{60} P_{x+n}^{E}-$ ${ }_{10} S_{x}^{T} \cdot{ }^{50} P_{x}^{E}$.

La estimación que se obtiene en esta forma está afectada por todos los errores ya descritos. A pesar de las limitaciones que entraña el tratar de mejorar estas estimaciones, se ha intentado introducir un

20Bogue, op. cit.

21 Para el ajuste se tomaron los nacimientos registrados durante 1945-1950 y se reconstruyeron sus cohortes con las defunciones registradas por edad en ese mismo periodo. 
Cuadro 8

México: Migráción NeTa intercensal estimada por el MÉtodo de íNdices DE SOBREVIVENCIA DE LAS TABLAS DE VIDA, POR ENTIDAD FEDERATIVA, 1950-1960

(En miles)

\begin{tabular}{|c|c|c|c|c|}
\hline Enticades & $\begin{array}{l}\text { lijigración neta } \\
\text { de } 10 \text { y más } \\
\text { arios de edad }\end{array}$ & $\begin{array}{l}\text { Migración neta } \\
\text { de } 0 \text { a } 9 \\
\text { años de edad }\end{array}$ & $\mathrm{Mi} \mathrm{cr}$ & $\begin{array}{l}\text { ión neta } \\
\text { tal }\end{array}$ \\
\hline $\begin{array}{l}\text { Agutscalientes } \\
\text { Baja California } \\
\text { Baja California } \mathrm{T} \text {. } \\
\text { Campeche } \\
\text { Coahuila } \\
\text { Colima } \\
\text { Chiapas } \\
\text { Chihuahua } \\
\text { Distrito Federal } \\
\text { Duraneo } \\
\text { Guanajuato } \\
\text { Guerrero } \\
\text { Hidalso } \\
\text { Jalisco } \\
\text { Mexico } \\
\text { Michoacán } \\
\text { Morelos } \\
\text { Nayarit } \\
\text { Muevo León } \\
\text { Oaxaca } \\
\text { Puebla } \\
\text { Querétaro } \\
\text { Quintana Roo } \\
\text { San Iuis Potos1 } \\
\text { Sinaloa } \\
\text { Sonora } \\
\text { Tabasco } \\
\text { Tamaulipas } \\
\text { Tlaxcala } \\
\text { Veracrua } \\
\text { Yucatán } \\
\text { Zacatecns }\end{array}$ & 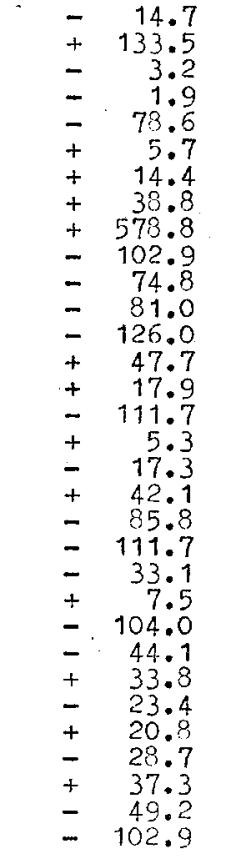 & $\begin{array}{lr} & 3.1 \\
+ & 17.7 \\
+ & 0.5 \\
+ & 0.2 \\
- & 22.3 \\
+ & 0.6 \\
+ & 3.6 \\
+ & 9.7 \\
+ & 29.9 \\
+ & 13.5 \\
- & 15.0 \\
+ & 13.0 \\
+ & 5.5 \\
+ & 13.0 \\
+ & 0.7 \\
+ & 1.5 \\
+ & 2.1 \\
+ & 1.9 \\
\pm & 2.9 \\
+ & 23.1 \\
+ & 15.5 \\
\pm & 4.7 \\
+ & 3.0 \\
+ & 15.0 \\
+ & 2.6 \\
+ & 2.2 \\
+ & 7.9 \\
\pm & 5.0 \\
+ & 4.4 \\
+ & 13.3 \\
- & 8.7 \\
+ & 22.0\end{array}$ & $\begin{array}{l}- \\
+ \\
- \\
+ \\
+ \\
+ \\
+ \\
- \\
- \\
+ \\
+ \\
+ \\
+ \\
+ \\
- \\
+ \\
+ \\
+ \\
+ \\
+\end{array}$ & $\begin{array}{r}17.8 \\
151.2 \\
2.7 \\
1.7 \\
100.9 \\
6.3 \\
18.0 \\
43.6 \\
612.8 \\
115.4 \\
89.8 \\
68.0 \\
120.5 \\
32.7 \\
18.6 \\
110.2 \\
7.4 \\
19.2 \\
39.2 \\
62.7 \\
95.2 \\
37.8 \\
10.5 \\
119.0 \\
41.5 \\
31.6 \\
15.5 \\
15.8 \\
33.1 \\
52.6 \\
57.9 \\
124.9\end{array}$ \\
\hline
\end{tabular}

ajuste que contribuya a la reducción de alguno de los errores. Concretamente, el ajuste se refiere a la corrección de los índices de sobrevivencia censales tomando en cuenta las diferencias regionales en mortalidad que se observan en México.

Para esto, se ha supuesto que los índices de sobrevivencia censales cumplen la función de corregir o al menos de reducir los errores por declaración errónea de edad y por subenumeración en las estructuras de la población censada. En cuanto a la sobrevivencia, teniendo en cuenta las tablas de vida de donde se derivan las diferencias en mortalidad que se dan entre las cuatro regiones en el período de estudio, es posible introducir un factor de corrección que contenga la diferencia entre la sobrevivencia de todo el país y la de la región a la que pertenezca la entidad. Es decir, que el monto de la migración corregida por diferencias en mortalidad será igual a: $M_{x+n}=\bar{M}_{x+n}+\Delta S_{x} \cdot{ }^{50} P_{x}^{E}$, 
en donde $\bar{M}_{x+n}$ es el monto de la migración que resulta de aplicar el índice de sobrevivencia censal de todo el país más un factor de corrección. Este factor equivale al producto de la diferencia entre los índices de sobrevivencia de la tabla de vida para el país y los índices de la región $\left(\Delta S_{x}\right)$ y el monto de la población de la entidad censada al comienzo de la década $\left({ }^{\tilde{j} 0} P_{* k}^{E}\right)$. Como puede verse, esta nueva estimación es el resultado de la combinación de índices censales e índices de las tablas de vida. Los índices y sus diferencias se dan en el cuadro 9.

\section{Cuadro 9}

MÉXICO: INDICES NACTONAL Y REGIONALES DE SOBREVIVENCIA POR GRUPOS DE EDAD, 1950-1960

\begin{tabular}{|c|c|c|c|c|c|c|c|}
\hline \multirow[t]{2}{*}{ Edad } & \multirow{2}{*}{$\begin{array}{c}\text { Nocional } \\
\text { yegrón III }\end{array}$} & \multicolumn{3}{|c|}{ remiones } & \multicolumn{3}{|c|}{$\begin{array}{l}\text { Diferencias entre los } \\
\text { indices nacionnles } \mathrm{y} \\
\text { los regionales }\end{array}$} \\
\hline & & $I$ & II & $I V$ & I & $I I$ & IV \\
\hline 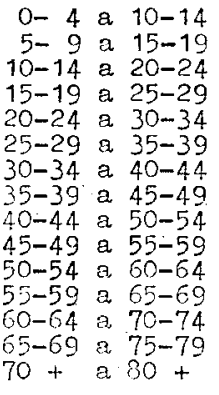 & $\begin{array}{l}.9275 \\
.9729 \\
.9718 \\
.9608 \\
.9500 \\
.9406 \\
.9298 \\
.9154 \\
.8943 \\
.8647 \\
.8240 \\
.9644 \\
.56993 \\
.0365\end{array}$ & $\begin{array}{l}.9643 \\
.9841 \\
.9003 \\
.9731 \\
.9659 \\
.9591 \\
.9505 \\
.9376 \\
.9180 \\
.8099 \\
.8483 \\
.7850 \\
.7001 \\
.5098 \\
.3029\end{array}$ & $\begin{array}{l}.9601 \\
.9822 \\
.9764 \\
.9683 \\
.9612 \\
.9542 \\
.9462 \\
.9337 \\
.9138 \\
.8338 \\
.9397 \\
.7712 \\
.6347 \\
.5730 \\
.2984\end{array}$ & $\begin{array}{l}.9017 \\
.0567 \\
.0511 \\
.0413 \\
.9308 \\
.9217 \\
.0030 \\
.069 \\
.8665 \\
.9365 \\
.7965 \\
.7356 \\
.6521 \\
.5477 \\
.2703\end{array}$ & $\begin{array}{l}-.0368 \\
-.0112 \\
-.0085 \\
-.0123 \\
-.0159 \\
=.0185 \\
=.0207 \\
=.0222 \\
=.0245 \\
=.0252 \\
=.0243 \\
=.0236 \\
-.0210 \\
=.0205 \\
-.0163\end{array}$ & $\begin{array}{l}-.0326 \\
-.0093 \\
-.0046 \\
-.0075 \\
-.0112 \\
-.0136 \\
=.0164 \\
=.0183 \\
-.0195 \\
=.0191 \\
-.0157 \\
-.0068 \\
-.0059 \\
-.0037 \\
-.0119\end{array}$ & $\begin{array}{l}.0258 \\
.0162 \\
.0207 \\
.0195 \\
.0192 \\
.0189 \\
.0268 \\
.0285 \\
.0277 \\
.0281 \\
.0275 \\
.0238 \\
.0270 \\
.0216 \\
.0162\end{array}$ \\
\hline rotal & .9128 & .9315 & .9275 & .9900 & -.0107 & -.0147 & .0228 \\
\hline$e_{0}^{o}$ & 54.31 & 61.00 & 59.80 & 47.95 & -6.69 & -5.49 & $6: 36$ \\
\hline
\end{tabular}

Regiones

Entidades

I Baja California, Distrito Federal, Nuevo León, Sinaloa y Tamaulipas.

II Baja California T., Coahuila, Chihuahua, Durango y Sonora.

III Aguascalientes, Campeche, Colima, Guanajuato, Jalisco, Michoacán, Morelos, Nayarit. Quintana Roo, Querétaro, San Luis Potosí, Tabasco, Veracruz, Yucatán y Zacatecas.

IV Chiapas, Hidalgo, Guerrero, México, Oaxaca, Puebla y Tlaxcala. Fuente: Benítez Zenteno y Cabrera, op. cit.

La estimación así obtenida comprende el número de migrantes intercensales de más de 10 años de edad que sobrevivieron a 1960. Para estimar la migración neta de las personas nacidas durante el período intercensal se siguió el proceso propuesto por Lee 22 mencionado con anterioridad (véase p. 348 ). Los resultados de esta estimación, que representan la migración neta de los niños con edades entre 0 y 9 años, fueron sumados a las estimaciones ajustadas para las edades de más de 10 años a fin de obtener la migración neta total.

Los resultados de los procesos anteriores aparecen en el cuadro 10. 


\section{Cuadro 10}

MÉXICO: MigRaCióN NETA INTERCENSAL ESTIMADA POR EL MÉTODO DE ÍNDICES DE SOBREVIVENCIA CENSALES, POR ENTIDAD FEDERATIVA, 1950-1960

(En miles)

\begin{tabular}{|c|c|c|c|c|c|}
\hline Entided & $\begin{array}{c}\text { Wigración } \\
\text { neta de } 10 \\
\text { y más años } \\
\text { de edad }\end{array}$ & $\begin{array}{c}\text { Corrección } \\
\text { por morta- } \\
\text { lidad re } \\
\text { Eional }\end{array}$ & $\begin{array}{c}\text { Migracion } \\
\text { neta ajug } \\
\text { tada de } \\
10 \text { y más } \\
\text { años de } \\
\text { edad a/ }\end{array}$ & $\begin{array}{l}\text { Migración } \\
\text { neta de o } \\
\text { a } 9 \text { años } \\
\text { de edad }\end{array}$ & $\begin{array}{l}\text { Migración } \\
\text { neta to } \\
\text { tal b7 }\end{array}$ \\
\hline (1) & (2) & (3) & (4) & (5) & (6) \\
\hline Aguascalientes & 9.1 & 0 & 9.1 & 2.5 & 11.4 \\
\hline Baja Calif & +127.2 & 4.2 & 123.0 & $+\quad 33.7$ & +156.7 \\
\hline Baja Califomia T. & $1 \cdot 3$ & -0.9 & 2.2 & -2.2 & 3.4 \\
\hline $\begin{array}{l}\text { Campeche } \\
\text { Coahuila }\end{array}$ & $\begin{array}{r}1.3 \\
41.2\end{array}$ & $\begin{array}{r}0 \\
-\quad 10.6\end{array}$ & 1.3 & $10 \frac{4}{6}$ & 62.7 \\
\hline Colima & 6.4 & & 6.4 & 1.3 & $\begin{array}{r}7.4 \\
7.7\end{array}$ \\
\hline Chis & 42.2 & $+\quad 20.7$ & 21.5 & 3.1 & 24.6 \\
\hline Chi hüahua & 44.4 & -12.5 & 31.9 & 4.2 & 36.1 \\
\hline Distrito Federal & 613.7 & $-\quad 57.0$ & +556.7 & 123.1 & +679.8 \\
\hline Durango & 69. & 9.3 & 73.7 & $24 \cdot 3$ & 103.0 \\
\hline $\begin{array}{l}\text { Guanajuato } \\
\text { Guerrero }\end{array}$ & $-\quad 59.2$ & & 59.2 & 18.8 & 78.0 \\
\hline & $\begin{array}{r}47.6 \\
-\quad 110.8\end{array}$ & $+\quad 20.9$ & 26.7 & 6.7 & $-\quad 33.4$ \\
\hline $\begin{array}{l}\text { idalso } \\
\text { alisco }\end{array}$ & $\begin{array}{r}110.8 \\
+\quad 60.0\end{array}$ & $+\begin{array}{r}19.4 \\
0\end{array}$ & $\begin{array}{l}91.4 \\
60.0\end{array}$ & $18 \cdot 3$ & $=109.7$ \\
\hline éxi & 9.6 & 31.7 & 22.1 & $\begin{array}{l}0.2 \\
4.4\end{array}$ & $\begin{array}{l}66.2 \\
26.5\end{array}$ \\
\hline Michoacán & 71.6 & 0 & 71.6 & 25.4 & 74.0 \\
\hline Morelos & 12.2 & 0 & 12.2 & 2.1 & + \\
\hline iNayarit & 5.3 & $\mathrm{O}$ & 5.3 & 2.9 & 8.2 \\
\hline Nuevo Ieón & 77.2 & 13.8 & 63.4 & 11.9 & 75.3 \\
\hline & 118.9 & 32.4 & 86. & $15 \cdot 9$ & 102.4 \\
\hline Puebla & $145 \cdot 3$ & 37.1 & 108.2 & $26 \cdot 2$ & 134.4 \\
\hline Querétaro & 25.0 & 0 & 25.0 & 6.4 & 31.4 \\
\hline Quintana Foo & 7.3 & 0 & 7.3 & 2.1 & 9.1 \\
\hline San Iuis Potosi & $82 \cdot 5$ & 0 & 82.5 & 21.8 & $-104 \cdot 3$ \\
\hline $\begin{array}{l}\text { Sinaloa } \\
\text { Sonora }\end{array}$ & $\begin{array}{l}23 \cdot 9 \\
58.2\end{array}$ & $=11.9$ & 35.8 & 18.2 & - \\
\hline $\begin{array}{l}\text { Sonora } \\
\text { Tabasco }\end{array}$ & $\begin{array}{l}58.2 \\
15.3\end{array}$ & $\begin{array}{r}-6 \\
0\end{array}$ & 50.6 & $9 \cdot 8$ & 60.4 \\
\hline $\begin{array}{l}\text { Tabasco } \\
\text { Tanaulipas }\end{array}$ & 44.3 & 13.4 & 30 : & 7.0 & $\begin{array}{l}20.8 \\
37.9\end{array}$ \\
\hline Tlaxcala & 27.8 & 6.5 & 21. & 6.0 & 27.3 \\
\hline Veracruz & 22.5 & 0 & 22. & 2.1 & 24.6 \\
\hline & 39. & 0 & 39. & 3. & 47.6 \\
\hline Zacatecas & 75 & 0 & 75.8 & 22.2 & 98.0 \\
\hline
\end{tabular}

a Suma algebraica de las columnas 2 y 3 .

b Suma algebraica de las columnas 4 y 5 .

IV. ESTIMACIÓN DE LA MIGRACIÓN NETA INTERCENSAL CON UTILIZACIÓN DE LAS ESTADÍSTICAS VITALES

La utilización de los registros de nacimientos y defunciones para estimar la migración interna se basa en la simple ecuación demográfica $P_{1}=P_{0}+$ nacimientos - defunciones + (inmigrantes - emigrantes), donde $P_{0}$ y $P_{1}$ se refieren a las poblaciones nativas de una entidad censadas al principio y al final del período intercensal; y los nacimientos y defunciones son los ocurridos en la entidad respectiva durante el intervalo considerado. 
De la anterior expresión se desprende que la migración neta $(M)$ definida como la diferencia entre inmigrantes y emigrantes, es función del cambio total de la población menos el crecimiento natural, es decir:

$$
M=\left(P_{I}-P_{0}\right)-(\text { nacimientos }- \text { defunciones })
$$

Este procedimiento, básicamente muy simple, necesita ciertas condiciones que hay que tomar en cuenta para su aplicación e interpretación. Estas condiciones son las siguientes:

a) si durante el período intercensal hubo migración internacional, tanto el cambio total de la población como el incremento natural deben ser ajustados;

b) los nacimientos y las defunciones deben ser tabulados o ajustados, respectivamente, al lugar de residencia de la madre y al lugar de residencia de la persona fallecida y no por lugar de ocurrencia. La medición de la migración neta con los registros de las estadisticas vitales tabuladas por lugar de ocurrencia tienden a contar cada nacimiento de una madre no residente como un emigrante y cada muerte de una persona no residente como un inmigrante;

c) es necesario que tanto los dos censos como los registros de nacimientos y defunciones sean exactos, es decir, libres de errores de subenumeración o subregistro.

En la práctica, los censos y registros continuos usados para estimar la migración neta no cumplen con todo rigor estas condiciones. De la misma forma que en el método de los índices de sobrevivencia, la mayor parte de los problemas que se encuentran en este procedimiento se deben al hecho de que las estimaciones que produce son de carácter residual, o sea que después de eliminados otros componentes de cambio, el remanente se toma como expresión de los movimientos migratorios.

En resumen, los montos estimados estarán afectados por un error cuyo tamaño dependerá de la combinación de los errores relativos en la información básica; en otras palabras, las estimaciones de la migración por este método serán una combinación de la migración neta y del balance neto de los errores en la información.

Siguiendo el proceso descrito, se estimó, para cada entidad, el monto de la migración neta intercensal utilizando las poblaciones enumeradas en los censos de 1950 y 1960 , corregidas por subenumeración en las edades de 0 a 4 años. Las poblaciones se refieren sólo a los nativos, es decir, no se incluye a la población nacida en el extranjero. Los nacimientos y las defunciones se tomaron sin modificación alguna de los registros oficiales del período 1950-1960. Los resultados aparecen en el cuadro 11. 
Cuadro 11

México: Migración Neta intercensal estimada poR EL MÉTodo DE ESTAdísticas viTALES, POR ENTIDAD FEDERATIVA, 1950-1960

(En miles)

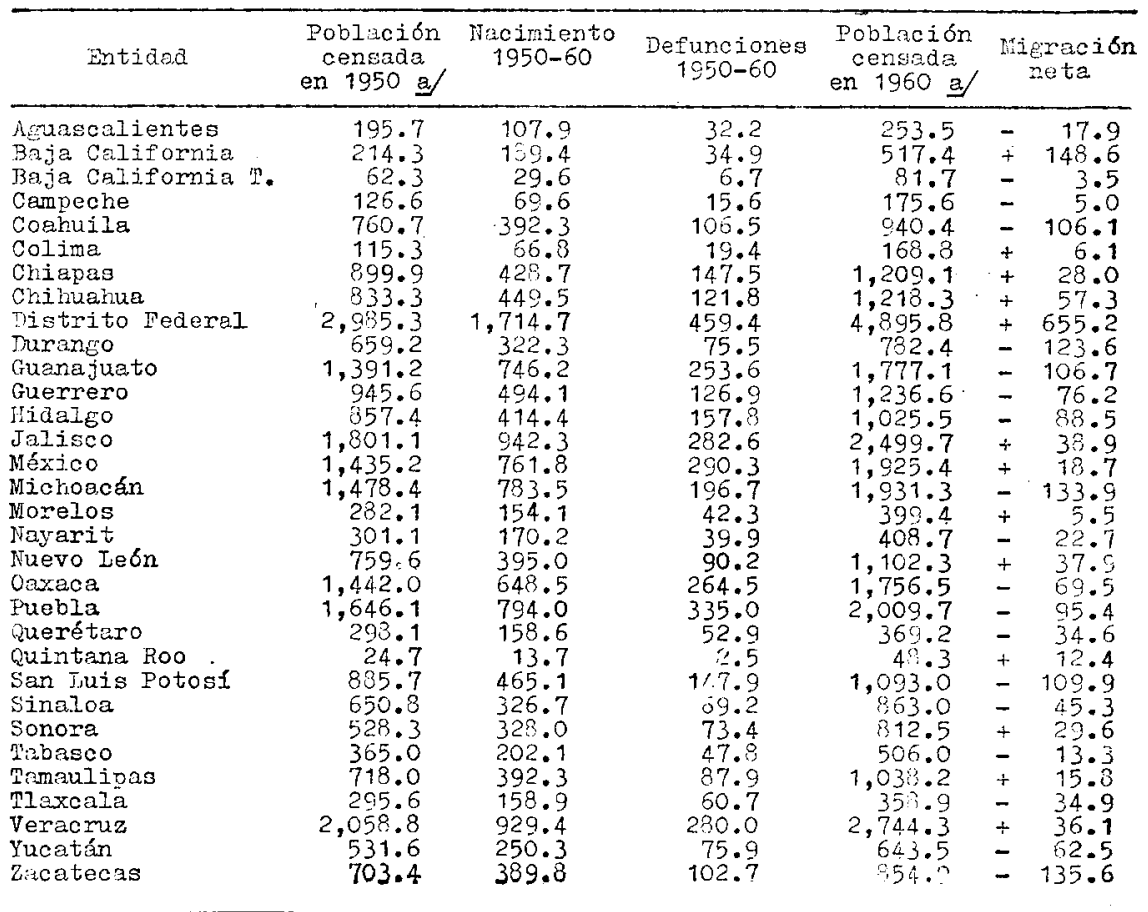

Fuentes: Dirección General de Estadística, VII Censo General de Población, Kesumen General, México, 1953; VIII Censo General de Población, Resumen General, México, 1963 y Anuarios Estadísticos de 1950 a 1960.

a Corregida por subenumeración en las edades de 0 a 4 años.

\section{Magnitud Y CARActerísticas de las DIFERENCIAS ENTRE LAS DIVERSAS ESTIMACIONES DE LA MIGRACIÓN NETA INTERCENSAL}

Los resultados de las cuatro estimaciones de la migración neta por entidad federativa se muestran en el cuadro 12 y en la gráfica 1. Las características generales sobresalientes que de inmediato se observan son las siguientes:

a) En primer término, es evidente que las cuatro estimaciones están altamente correlacionadas; la distribución general de la migración neta entre las entidades es aproximadamente la misma en la mayor parte de los casos.

b) Parece que existe mayor aproximación entre los resultados de los métodos de lugar de nacimiento (LN) e índices de sobre- 
vivencia censales (ISC) y los de índices de sobrevivencia de las tablas de vida (ISTV) y estadísticas vitales (EV). En estos últimos, sus magnitudes muestran movimientos casi iguales.

c) No obstante, en algunos estados existen diferencias substanciales en el monto de su migración neta, según los métodos usados; en algunos casos las diferencias son del ciento por ciento.

d) Existen cuatro entidades que tienen signos diferentes en el balance de su migración. Es decir, que de acuerdo con un método, la estimación del saldo de la migración en una entidad indica ganancia de población migrante, mientras que las

\section{Cuadro 12}

MÉxico: Migración Neta intercensal estimada por Diversos MÉTODOS, POR ENTIDAD FEDERATIVA, 1950-1960

(En miles)

\begin{tabular}{|c|c|c|c|c|}
\hline Entidades & $\begin{array}{l}\text { Iusar de } \\
\text { naci- } \\
\text { miento }\end{array}$ & $\begin{array}{c}\text { Indices de } \\
\text { sobreviven } \\
\text { cia censa- } \\
\text { Jes }\end{array}$ & $\begin{array}{c}\text { Inaices de } \\
\text { sobreviyen } \\
\text { cia de tal } \\
\text { blas de } \\
\text { vida }\end{array}$ & $\begin{array}{c}\text { Estadisticas } \\
\text { Vutales }\end{array}$ \\
\hline 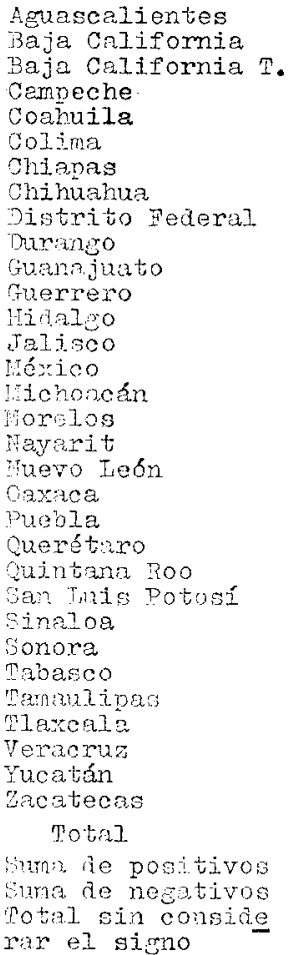 & 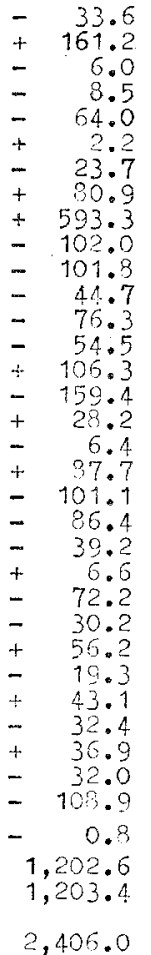 & 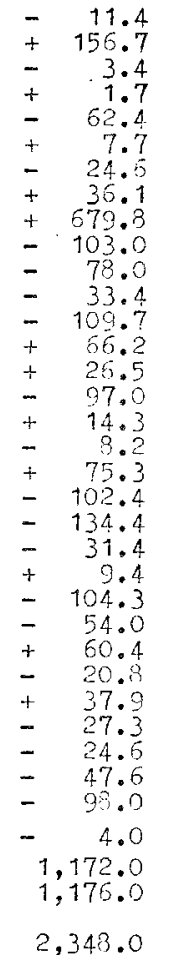 & 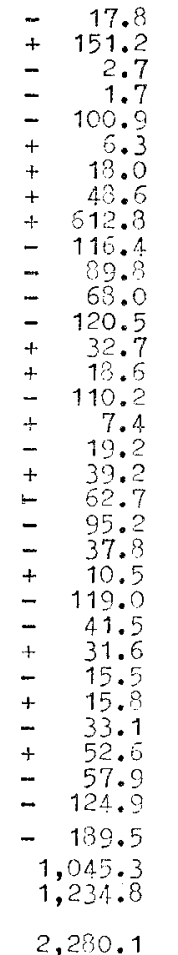 & 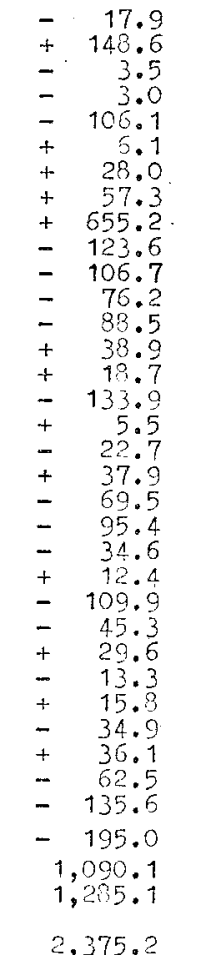 \\
\hline
\end{tabular}

Fuente: cuadros $7,8,10$ y 11 . 


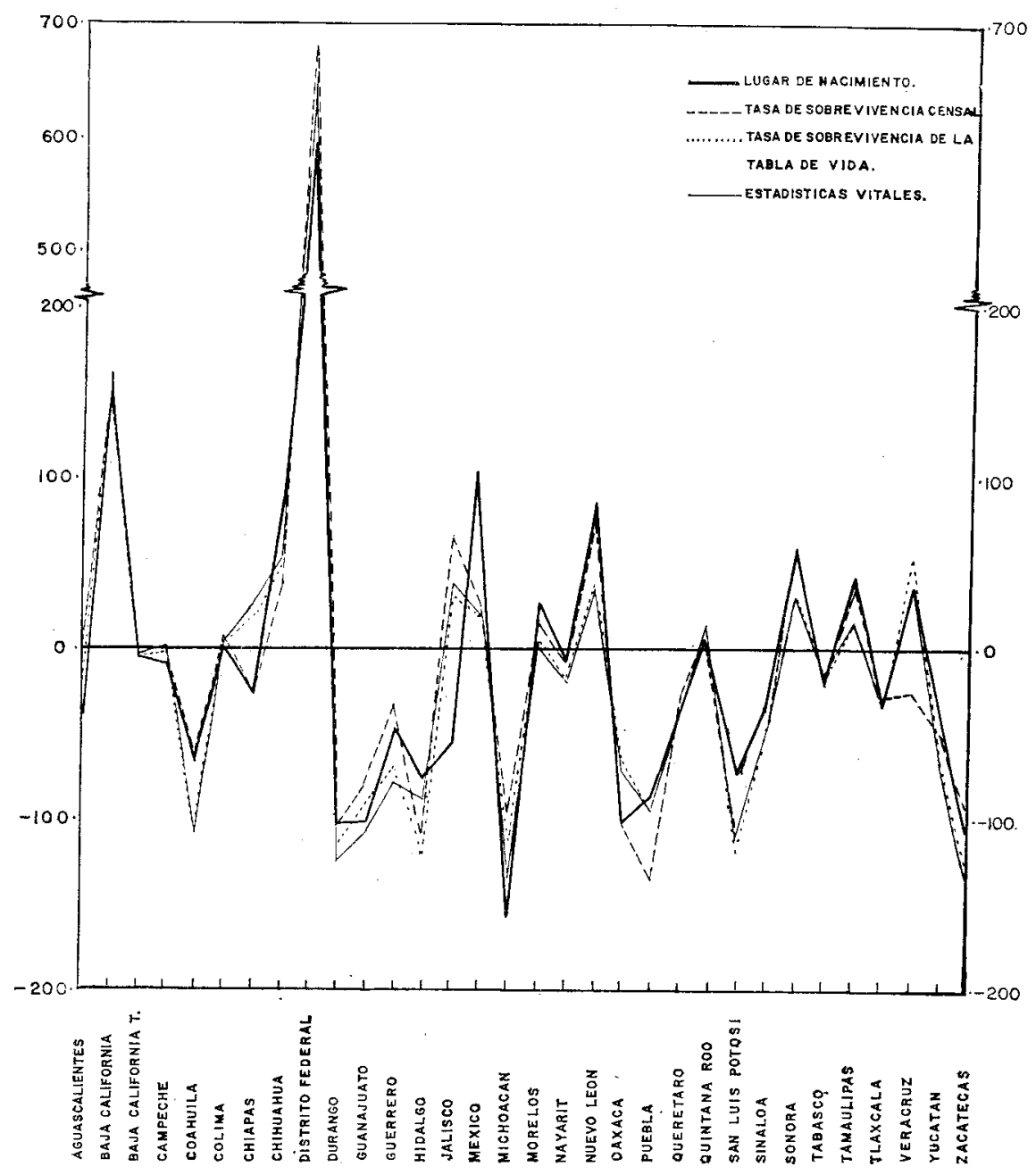

Gráfica 1

MÉxico: Migración Neta INTERCEnSal estimada POR diversos MÉtodos, 1950-1960 estimaciones mediante otro método indican pérdida. Estas entidades son Campeche, Chiapas, Jalisco y Veracruz.

e) No se aprecia que las estimaciones con un método sean siempre mayores o menores con respecto a las estimaciones con los otros métodos.

Examinando con más detalle los resultados, se observa que en los métodos LN e ISC las sumas algebraicas de la migración de las entidades son prácticamente cero. Esto indica que no obstante los ajustes 
introducidos, éstos tuvieron la propiedad de compensarse entre sí conservando la característica de que el número de inmigrantes sea igual al número de emigrantes. Sin embargo, la principal razón de esta situación se debe a la propia naturaleza de los métodos utilizados, que garantizan el cumplimiento de esta condición. En el método LN es obvia la explicación. En el caso del ISC, la aplicación de los índices de sobrevivencia representativos del total del país a las poblaciones de los estados asegura que la suma algebraica de los saldos migratcrios de las entidades dé un valor muy cercano a cero, sin querer decir esto que los montos de dicha migración representen los verdaderos. Es decir, aun cuando los índices de sobrevivencia disminuyan la influencia tanto de la migración internacional ocurrida durante el intervalo como de los errores en la distribución por edad de las poblaciones censales, sigue existiendo subestimación o sobrestimación de los montos de la migración, en sentidos opuestos, lo que da como resultado una compensación cuando se efectúa la suma de ellos.

Este equilibrio no se presenta en las estimaciones de ISTV y EV, donde los valores de la suma algebraica son - 189500 y -195000 , respectivamente. En estos métodos los montos de la migración están directamente afectados tanto por la migración internacional como por los errores censales. Esto quiere decir que cada entidad incorpora, en toda su magnitud, el efecto combinado de los errores y los mezcla con los verdaderos montos de la migración. Si se supone que los errores en la información censal debidos a la declaración errónea de la edad se compensan entre sí y que el ajuste por subenumeración en el grupo de 0 a 4 años de edad fue suficiente, una estimación del monto de la migración neta internacional en México sería de -189500 personas según el método ISTV y una estimación de la emigración internacional de la población de México sería de - 195000 personas según el método EV.

Las estimaciones dadas por ISTV y EV están subestimadas para las entidades con balance positivo en su migración y sobrestimadas en las entidades con balance negativo, tomando en cuenta que existe un saldo negativo en la migración internacional. En cuanto a la influencia que tiene el grado de enumeración de los censos de 1950 y 1960, no se tienen elementos para juzgar en qué dirección están desviadas las estimaciones.

Las estimaciones de LN están subestimadas por el simple hecho de que, al llevarse a cabo los censos, la población no informe su entidad de nacimiento o declare erróneamente su entidad de residencia como la entidad de su nacimiento. La corrección realizada por las muertes intercensales de los migrantes disminuye notablemente la principal falla de este método.

En cuanto a las entidades que acusan diferentes signos en sus saldos migratorios según las estimaciones (Campeche, Chiapas, Jalisco y Veracruz; véase el cuadro 12), la situación se resume en la forma siguiente:

Las diferencias de Campeche no son significativas, ya que su saldo migratorio es muy reducido en todas las estimaciones, y una ligera perturbación en los elementos de información empleados para su cálculo puede fácilmente producir distorsiones que en la práctica no 
son de importancia. Los tres restantes estados sí difieren en forma apreciable y resulta difícil dar alguna explicación sobre los motivos que causan la inversión del sentido de las corrientes migratorias. En Chiapas, los métodos de LN e ISC estiman un saldo negativo con montos muy parecidos, mientras que las dos estimaciones restantes son positivas. En este caso podría pensarse que la dirección correcta de las estimaciones sería la que proporcionen los primeros métodos, ya que algunas características de orden socioeconómico de la entidad corresponden más bien a un centro de repulsión que de atracción: alto índice tanto de población rural como de población dedicada a la agricultura, elevada proporción de población indígena y de analfabetismo, etc. Estas simples consideraciones, unidas a la posibilidad de un fuerte subregistro en los nacimientos, así como una mayor subenumeración en la población de 1950 que en la de 1960 (datos en los que se basan los métodos de ISTV y EV), llevaría a tener más confianza en las estimaciones dadas por los primeros métodos.

En Jalisco, se observa que LN da una estimación con saldo negativo mientras que conforme a los tres métodos restantes las estimaciones son positivas. Una explicación de esta situación sería artificial y en forma objetiva sólo podría decirse que Jalisco debería tener un saldo positivo por tratarse de un estado que contiene a la segunda ciudad de mayor población en el país (Guadalajara), con elevada tasa de crecimiento ( $7 \%$ anual), en donde se desarrolla una intensa actividad comercial e industrial; y porque en los últimos años se han realizado fuertes inversiones en obras de infraestructura que seguramente han atraído considerable mano de obra de otras entidades.

Por último, en Veracruz, las estimaciones LN, ISTV y EV producen saldos positivos mientras que ISC lo da negativo. Como en el caso anterior, no hay elementos para afirmar cuál sería la verdadera dirección. Las características económicas parecen ser favorables para que Veracruz sea un estado de moderada atracción.

En resumen, las diversas estimaciones producen sólo unos cuantos casos con diferentes signos en sus saldos migratorios. No teniendo elementos para juzgar la verdadera dirección de las corrientes migratorias, se han hecho apenas breves comentarios sobre este problema. No obstante, se piensa que, excepto en el caso de Jalisco, las verdaderas direcciones de la migración están dadas por el método LN.

Las magnitudes de las diferencias entre las cuatro estimaciones, pueden apreciarse en el cuadro 13 y en la gráfica 2, y, en forma resumida, en el cuadro 14. Ninguna de estas cantidades debe ser interpretada como una medida del error absoluto. El tomar como error absoluto a cualquiera de ellas implicaría que una de las estimaciones fuera estrictamente correcta. De hecho, todas ellas contienen errores y sus divergencias indican sólo las diferencias absolutas entre las diversas estimaciones.

En primer término, se observa que las diferencias mayores se dan entre las estimaciones de LN y las de EV ( $\sin$ tomar en cuenta los signos, dan una diferencia total de 760300$)$; las diferencias menores se encuentran entre los métodos ISTV y EV (diferencia total de 237100 ). 
CABRERA: MIGRACIÓN INTERNA EN MÉXICO

\section{Cuadro 13}

MÉxico: Desviaciones absolutas entre las DIVERSAS estimaciones DE LA MIGRACIÓN NETA INTERCENSAL POR ENTIDAD FEDERATIVA, 1950-1960 (En miles)

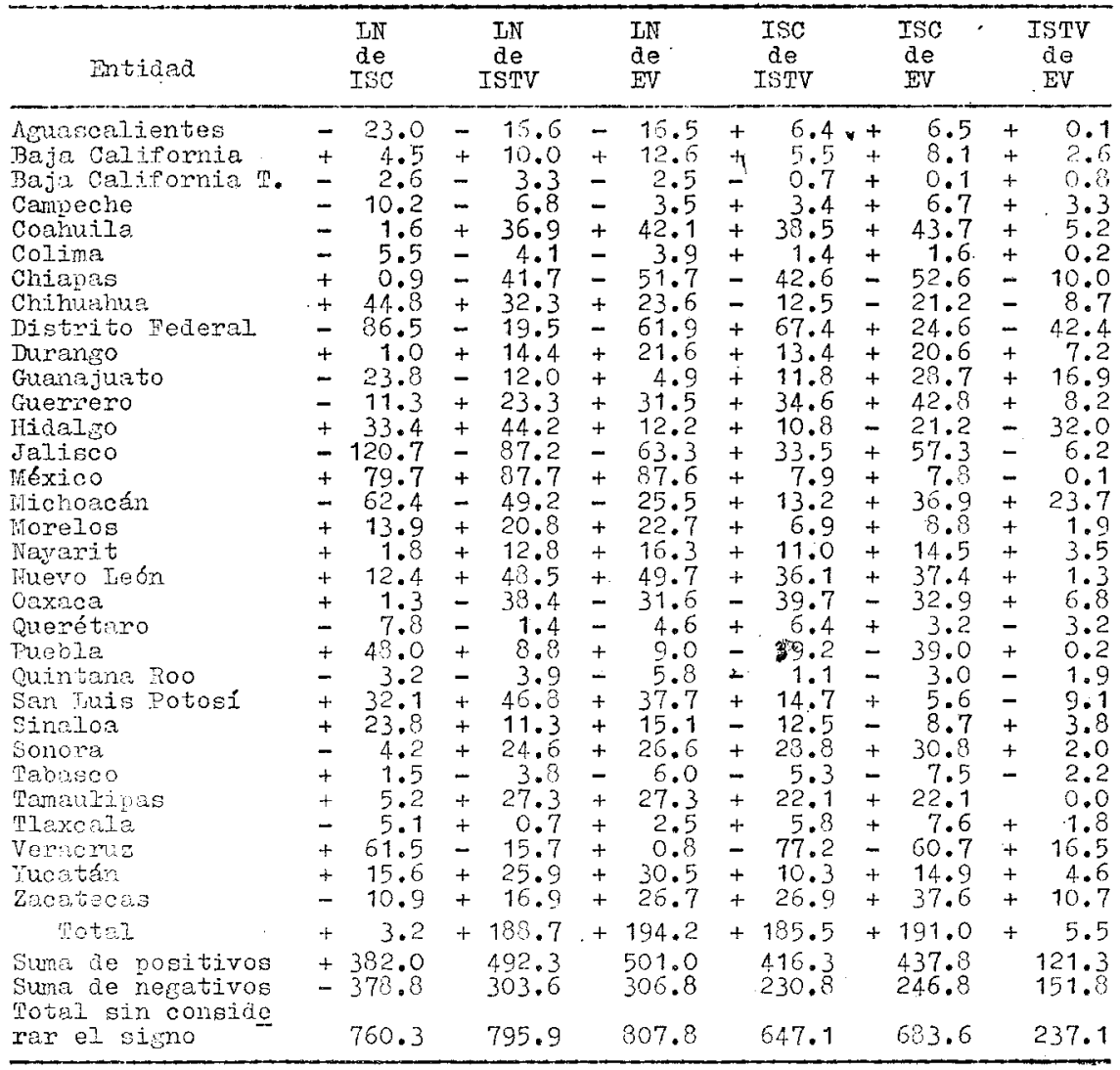

Fuente: cuadro 12.

Al efectuar un examen de las desviaciones frente a otras características tales como tamaño y dirección de la migración y tamaño de la población, destaca que:

a) los montos de las desviaciones tienen muy poca relación con los montos de las estimaciones;

b) no hay relación sistemática entre el monto de las desviaciones y la dirección de la migración;

c) existe importante grado de asociación entre el tamaño de la población y los montos de las desviaciones. Los estados con desviaciones de 30000 o más en cada par de estimaciones pertenecen a las entidades que mayor población tuvieron 

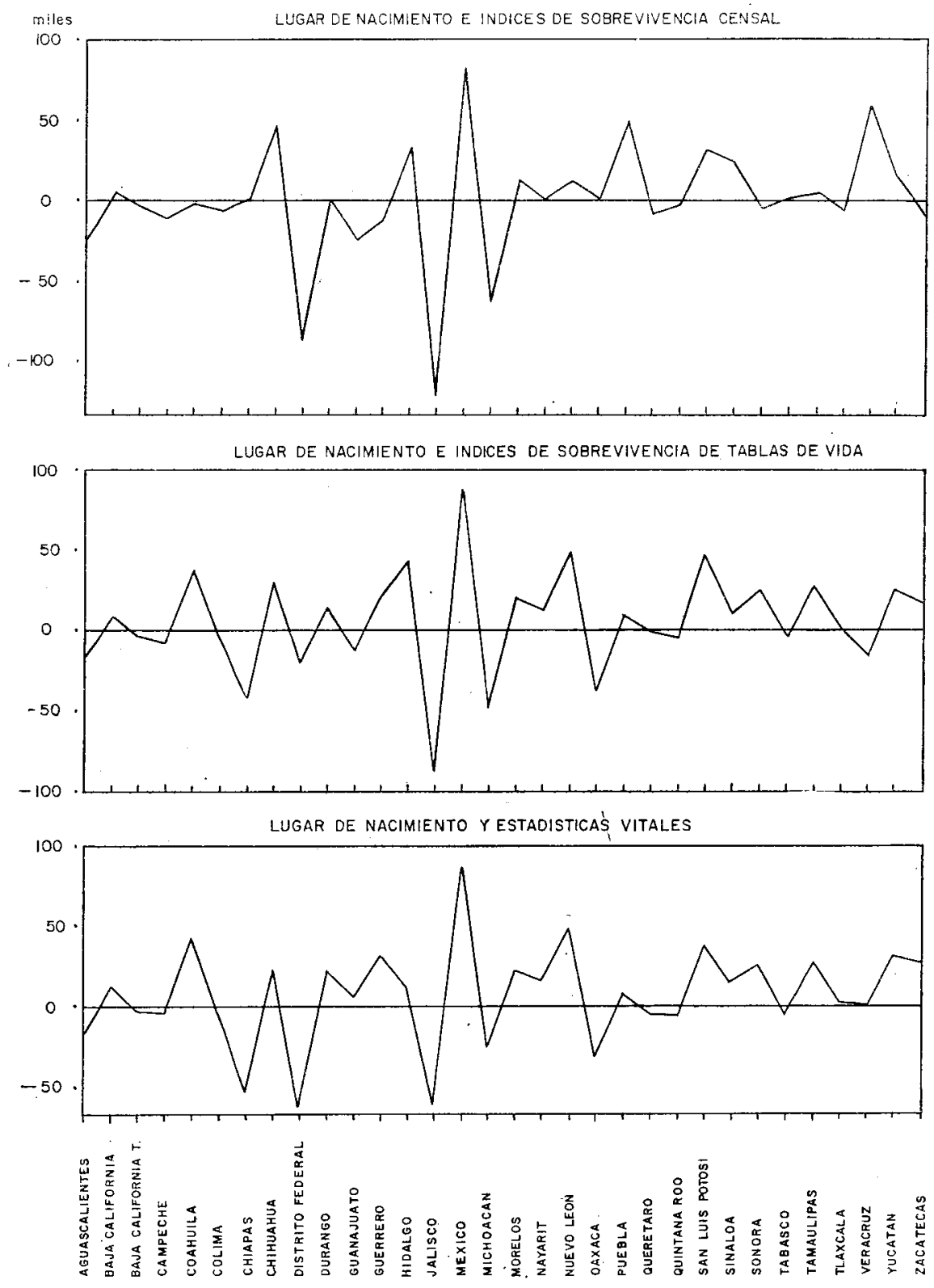

Gráfica 2

MÉxico: Desviaciones absolutas entre estimaciones de Migración NETa INTERCENSAL, 1950-1960 

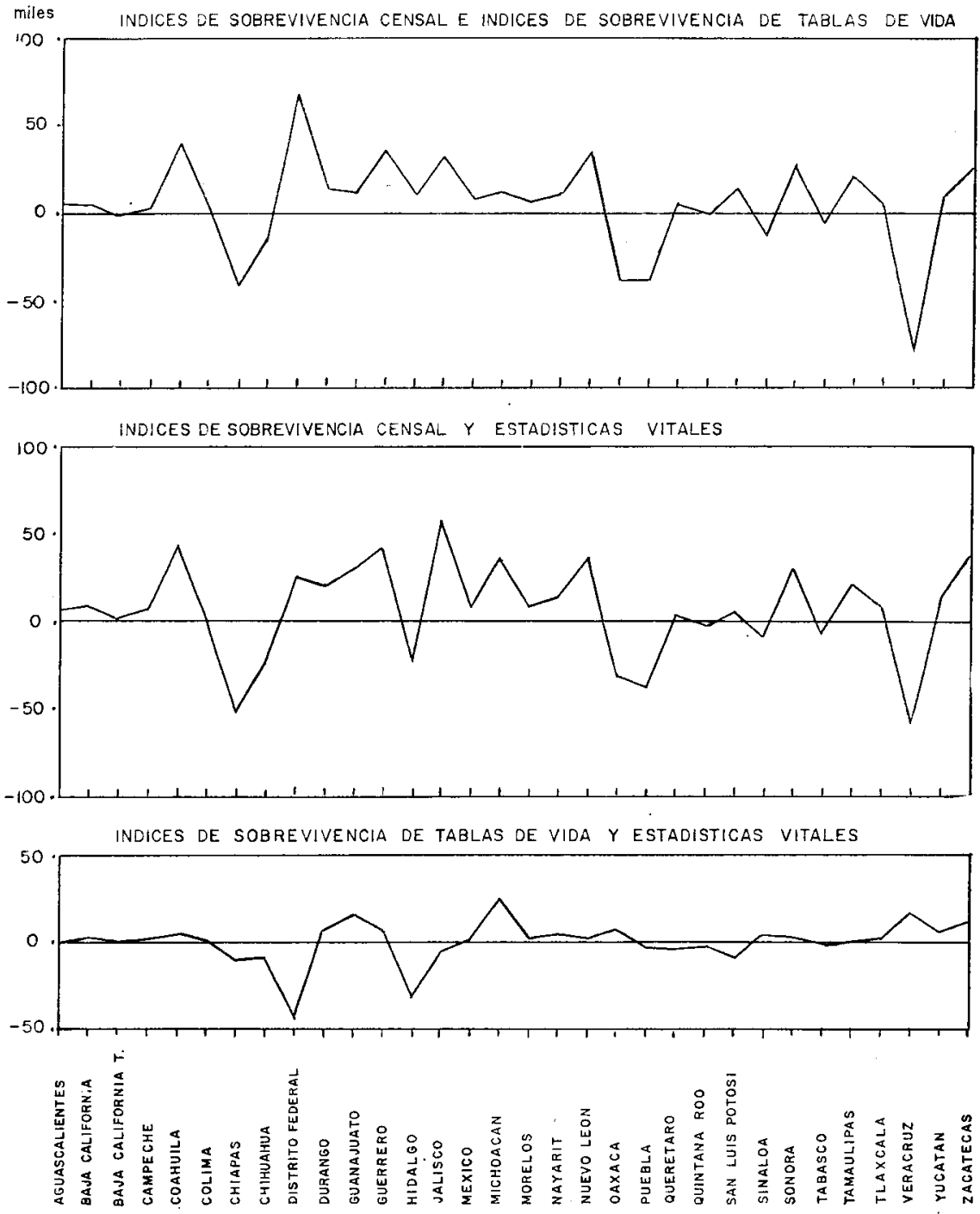

Gráfica 2 (Cont.)

MÉxico: Desviaciones absolutas entre estimactones de migración NETA INTERCENSAL, $1950-1960$ 


\section{Cuadro 14}

México: Distribución de las entidades federativas Según tamaño de las desviaciones ENTRE LAS DIVERSAS ESTIMACTONES

(Montos absolutos en miles)

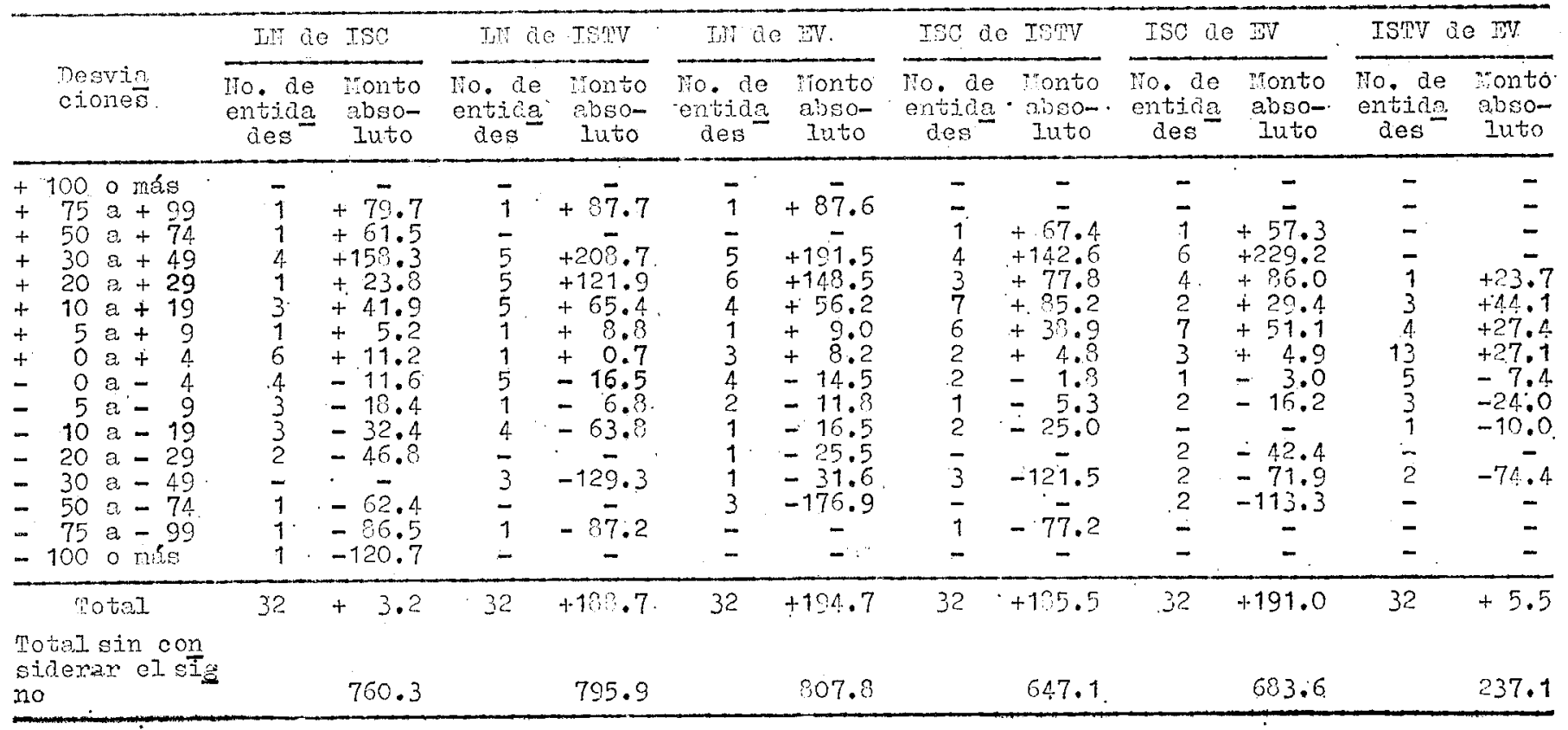

Fuente: cuadro 13. 
en 1950 y 1960. Las 10 entidades con mayores desviaciones están comprendidas entre las primeras 14 entidades de mayor población en 1950 y entre las primeras 12 en 1960. Esto podría indicar que las mismas fuentes de error estuvieran operando en todas las estimaciones.

Dentro de las posibles fuentes de error, es difícil decir cuál de ellas tiene más impacto en las estimaciones, ya que la misma fuente de error puede actuar en diferente forma según el método empleado.

El efecto de utilizar índices de sobrevivencia desviados puede considerarse de poca influencia en las estimaciones, debido a que en todos los casos se utilizaron las mismas fuentes de información para su cálculo: en los métodos LN e ISC hubo ajustes por mortalidad regional basados en los índices de sobrevivencia de la tabla de vida; en las estimaciones de ISTV se utilizaron directamente estos índices; y en las estimaciones de EV se usaron los registros de defunciones en los cuales se basan precisamente las tablas de vida (debido a esto los resultados entre estos dos últimos métodos son tan significativamente cercanos). Esto quiere decir que si los índices de sobrevivencia están desviados y no representan la verdadera mortalidad, se tendrá aproximadamente la misma influencia en todos los métodos.

El problema de la migración internacional sí puede tener efectos importantes en las diferencias y en algunos casos podrían explicarse a través de esto. Este tipo de error se refleja en forma diferente en cada estimación: en primer término, el método LN no considera en absoluto la población nacida en el exterior, es decir, los resultados están libres de esta influencia; en las estimaciones de ISC, tanto el índice de sobrevivencia como las poblaciones al principio y al final del período están afectadas por la población extranjera. Sin embargo, las propiedades que dicho método tiene hacen que se disminuya el error que introduce la migración externa al distribuirla entre todas las entidades. El método ISTV incorpora en toda su magnitud los montos de la migración externa y los mezcla con los movimientos internos, de aquí que la suma algebraica de los volúmenes migratorios de las entidades refleje en parte los movimientos internacionales. Zsta misma situación se presenta en las estimaciones de EV.

Por último, el papel que juegan en las estimaciones los diferentes grados de enumeración en los dos censos ${ }^{23}$ puede ser definitivo en las diferencias que se presentan. En el caso de la migración internacional, el método ISC disminuye este error en sus estimaciones, los métodos ISTV y EV lo asimilan en su totalidad y el LN tiene diferente fuente de error ya que no se está trabajando con poblaciones totales sino únicamente con la población que reporta estar viviendo en un estado diferente al de su nacimiento. Pero la pregunta sobre si el censo de 1960 fue enumerado mejor que el de 1950, en términos absolutos más que en relativos, no puede ser contestada con toda certeza, y aun cuando hubiera ciertos indicios de que así fuera, queda todavía el problema de estimar para cada entidad los errores absolu-

23 Hope T. Eldrige llama a esto "error neto censal", significando el monto en que difieren la subenumeración neta del primer censo y la del segundo. Véase Net Intercensal Migration for State and Geographic Divisions of the United States, 1950-1960, Universidad de Pennsylvania, 1965. 
tos en los dos censos. Por lo tanto, queda abierta la pregunta del efecto de los diferentes grados de enumeración de los censos en las estimaciones de la migración neta de entidades individuales.

Por último, la pregunta de cuál de los métodos proporciona la mejor estimación no puede ser contestada en forma definitiva. Sólo teóricamente puede ser normado un criterio sobre este problema, que en la práctica puede no ser confirmado.

De los comentarios hechos a cada método se puede llegar a la conclusión de que en general, en los países con características de información censal semejantes a las de México, las estimaciones de la migración neta obtenidas por el método de lugar de nacimiento, si se corrigen por mortalidad, son probablemente las que menos estén afectadas por errores en la enumeración, en los índices de sobrevivencia u originados en la migración internacional. En forma teórica, esta conclusión se puede apreciar claramente. A continuación se examina sólo una de las tres fuentes de error, que se refiere a los errores en los índices de sobrevivencia.

Si denotamos como $S$ el índice de sobrevivencia de toda la población, suponiendo que este índice sea válido para migrantes y no migrantes, la migración neta de una entidad estimada por el método LN estará dada por la expresión:

$$
M^{\prime}=\left(I_{1}-S I_{0}\right)-\left(O_{1}-S O_{0}\right)
$$

donde $I_{0}$ e $I_{1}$ son el número de personas enumeradas en una entidad diferente a la de su nacimiento, en el primero y segundo censos, respectivamente; y $O_{0}$ y $O_{1}$ el número de personas nacidas en una entidad y enumerada en otra en los dos censos.

La migración neta estimada por los métodos de índices de sobrevivencia será igual a:

$$
M^{\prime \prime}=P_{1}-S P_{0}
$$

donde $P_{0}$ es la población total de una entidad en el primer censo y $P_{1}$ la población total de 10 años y más enumerada en el segundo censo.

Esta última expresión puede escribirse en otra forma:

$$
M^{\prime \prime}=\left(N_{1}+I_{1}\right)-S\left(N_{0}+I_{0}\right)
$$

ya que $P_{0}=N_{0}+I_{0}$ y $P_{1}=N_{1}+I_{1}$, es decir, la población enumerada en el primer censo $\left(P_{0}\right)$ es igual a la población nativa $\left(N_{0}\right)$ más la población nativa de otras entidades $\left(I_{0}\right)$. La misma situación se presenta con la población enumerada en el segundo censo $\left(P_{1}\right)$.

Arreglando los términos en otra forma se tendrá:

$$
M^{\prime \prime}=\left(I_{1}-S I_{0}\right)+\left(N_{1}-S N_{0}\right)
$$

Esta expresión produce la misma estimación que la obtenida por el lugar de nacimiento $\left(M^{\prime}\right)$, si la población está correctamente enumerada y el índice de sobrevivencia es también correcto. Significa que los últimos términos de $M^{\prime}$ y $M^{\prime \prime}$ son iguales:

$$
\left(N_{1}-S N_{0}\right)=\left(O_{1}-S O_{0}\right)
$$


Ahora, si las poblaciones fueron enumeradas correctamente, pero el índice de sobrevivencia no representa el nivel verdadero de la mortalidad de la entidad, los errores en las estimaciones serán los siguientes:

Si denotamos con $\Delta S$ la diferencia entre el índice de sobrevivencia correcto y el no correcto, $\bar{M}^{\prime}$, será, según el método LN:

$$
\begin{aligned}
\bar{M}^{\prime} & =\left(I_{1}-O_{1}\right)-S\left(I_{0}-O_{0}\right)+\Delta S\left(I_{0}-O_{0}\right) \\
& =M^{\prime}+\Delta S\left(I_{0}-O_{0}\right)
\end{aligned}
$$

y en los métodos de índices de sobrevivencia:

$$
\begin{aligned}
\bar{M}^{\prime \prime} & =\left(N_{1}+I_{1}\right)-S\left(N_{0}+I_{0}\right)+\Delta S\left(N_{0}+I_{0}\right) \\
& =P_{1}-S P_{0}+\Delta S P_{0} \\
& =M^{\prime \prime}+\Delta S P_{0}
\end{aligned}
$$

Dado que $P_{0}$ es una cantidad mucho mayor que $\left(I_{0}-O_{0}\right)$, es obvio que el error en $\bar{M}^{\prime \prime}$ será mucho más grande que en $\bar{M}^{\prime}$.

El efecto en las estimaciones de la migración debido a los errores de enumeración es más o menos similar al originado en los índices de sobrevivencia. En la misma forma, los errores debidos a la migración internacional serán mucho menores en el método de lugar de nacimiento que en los métodos de índices de sobrevivencia o estadísticas vitales.

Una última observación general acerca de este estudio es que cualquiera de los métodos que han sido presentados puede ser muy útil para diferentes propósitos o circunstancias. El método de lugar de nacimiento es importante en cuanto que proporciona información sobre los montos de los inmigrantes y emigrantes por separado, y ofrece la posibilidad de realizar análisis de las corrientes migratorias en cada entidad, aunque hay la limitación de no poder estimar la estructura por edad de los migrantes. El método de los índices de sobrevivencia censales es muy práctico en su forma de cálculo y produce estimaciones para unidades geográficas pequeñas (municipios), facilitando además la comparación a través del tiempo; en otro sentido también es útil para la estimación de la estructura por edad de los migrantes intercensales. Probablemente, la mejor aplicación del método de índices de sobrevivencia de las tablas de vida es en las proyecciones de población a nivel regional. Por último, el método de estadísticas vitales proporciona estimaciones que no son tan inexactas como usualmente se piensa y que pueden ser utilizadas cuando no exista información más detallada. 